\title{
Emerging Significance of Flavonoids as P-Glycoprotein Inhibitors in Cancer Chemotherapy
}

\author{
Tripta Bansal ${ }^{\star 1}$, Manu Jaggi ${ }^{1}$, Roop K Khar ${ }^{2}$ and Sushama Talegaonkar ${ }^{\star 2}$ \\ ${ }^{1}$ Deptartment of Preclinical Research, Dabur Research Foundation, U.P., India \\ ${ }^{2}$ Deptartment of Pharmaceutics, Jamia Hamdard, Hamdard University, Hamdard Nagar, New Delhi, India
}

Received November 20, 2008; Revised February 4, 2009; Accepted March 29, 2009; Published March 31, 2009.

\begin{abstract}
Chemotherapy forms the mainstay of cancer treatment particularly for patients who do not respond to local excision or radiation treatment. However, cancer treatment by drugs is seriously limited by P-glycoprotein (P-gp) associated multi-drug resistance (MDR) in various tumor cells. On the other hand, it is now widely recognized that P-gp also influences drug transport across various biological membranes. P-gp transporter is widely present in the luminal surface of enterocytes, biliary canalicular surface of hepatocytes, apical surface of proximal tubular cells of kidney, endothelial cells of blood brain barrier, etc. thus affecting absorption, distribution, metabolism and excretion of xenobiotics. Clinical significance of above mentioned carrier is appreciated from the fact that more than fifty percent of existing anti-cancer drugs undergo inhibitable and saturable P-gp mediated efflux. Consequently, there is an increasing trend to optimize pharmacokinetics, enhance antitumour activity and reduce systemic toxicity of existing anti-cancer drugs by inhibiting P-gp mediated transport. Although a wide variety of P-gp inhibitors have been discovered, research efforts are underway to identify the most appropriate one. Flavonoids (polyphenolic herbal constituents) form the third generation, non-pharmaceutical category of P-gp inhibitors. The effects produced by some of these components are found to be comparable to those of well-known P-gp inhibitors verapamil and cyclosporine. Identification of effective P-gp modulator among herbal compounds have an added advantage of being safe, thereby making them ideal candidates for bioavailability enhancement, tissue-penetration (e.g. blood brain barrier (BBB)), decreasing biliary excretion and multi-drug resistance modulating agents. The dual effects, i.e. P-gp modulation and antitumor activity, of these herbal derivatives may synergistically act in cancer chemotherapy. This paper presents an overview of the investigations on the feasibility and application of flavonoids as P-gp modulators for improved efficacy of anti-cancer drugs like taxanes, anthracyclines, epipodophyllotoxins, camptothecins and vinca alkaloids. The review also focuses on flavonoiddrug interactions as well as the reversal activity of flavonoids useful against MDR. In addition, the experimental models which could be used for investigation on P-gp mediated efflux are also discussed.
\end{abstract}

\section{INTRODUCTION}

Tumour treatment with chemotherapeutic agents is hindered by the development of multi-drug resistance (MDR), a poor and/or highly variable oral bioavailability and low tissue distribution of drugs. MDR is defined as the ability of tumours to show resistance to a broad range of structurally and functionally unrelated drugs when exposed to a single drug. MDR could be "intrinsic", when disease is refractory to chemotherapy at diagnosis or "acquired", when the drug becomes insensitive after treatment. Of the various mechanisms mediating MDR, resistance conferred by $\mathrm{P}$ glycoprotein (P-gp) transporter is best characterized and is of considerable clinical importance (1).

Corresponding author: Tripta Bansal, Dept. of Pharmaceutics, Faculty of Pharmacy, Jamia Hamdard, Hamdard University, Hamdard Nagar, New Delhi, India, Email: dr.tripta@gmail.com; stalegaonkar@gmail.com 
P-gp is the efflux pump discovered in 1976 (2) due to its expression in various types of MDR tumors (3). It is encoded by MDR1 gene in humans and the mdr1-a and mdr1-b genes in rodents. P-gp is over-expressed in many intrinsically resistant tumors (leukemias, lymphomas, adult and childhood sarcomas and neuroblastomas) and those that acquire resistance during chemotherapy treatment (1).

Advances in biotechnological field proved the presence of P-gp not only in tumor cells but also in wide variety of normal tissues where they have a role to play in absorption, distribution, metabolism and excretion. P-gp is found to be present in the biliary canalicular surface of hepatocytes, luminal surface of cells of jejunum and colon, apical surface of proximal tubular cells of kidney, endothelial cells of blood brain barrier, apical membrane of fetal-membrane barrier function in placenta and in other tissues like lungs, adrenals, prostrate, skin, spleen, heart and skeletal muscle. P-gp in these can be viewed as a barrier which prevents entry of xenobiotics into the body, remove them once they have entered, protect cells and keep toxic substances into circulation, especially when certain tissues are sensitive to adverse effects (4). The role of Pglycoprotein in human pharmacology and its clinical significance has been extensively reviewed (3-9). P-gp mediated efflux affects each step which a drug comes across during its stay in the body. It influences absorption through intestinal carriers, which expel drug molecules back into the lumen; distribution, by preventing drug entry into tissues like brain; metabolism, as it acts synergistically with cytochrome P450 3A4 (CYP 3A); excretion, by affecting both biliary and renal tubular function (10). Significance of above mentioned carrier is appreciated from the fact that more than fifty percent of existing anticancer drugs undergo P-gp mediated efflux (Table 1). Taxane anticancer drugs (e.g. paclitaxel, docetaxel) have low systemic exposure due to their ability to be effluxed by P-gp. The correlation between area under curve (AUC) after oral administration and P-gp content suggests that P-gp in gut wall determines the plasma concentration of P-gp substrates. The crucial role played by P-gp in modulating distribution is demonstrated by the increased concentration of vinblastine and doxorubicin in brains of knockout mice compared to the wild type. Drug-drug interactions involving P-gp are also common due to broad substrate specificity.
Given the role of P-gp in influencing drug's pharmacology, methods to overcome P-gp mediated efflux have been investigated. This has resulted in the development of several generations of P-gp inhibitors over past two decades. Unfortunately, the results of studies aimed at overcoming multidrug resistance and improving oral drug treatment in cancer patients by the concomitant use of first- or second-generation Pgp inhibitors and anticancer drugs have been disappointing. Their clinical applicability was found to be limited and consequently there is an ongoing, continuous search to identify more effective and safe P-gp inhibitors $(11,12)$. The ideal P-gp inhibitor is the one which is non-toxic and does not have any pharmacological activity of its own.

Herbal components form the ideal P-gp inhibitors as they have been consumed since long with a view to improve health status of humans. The present paper reviews the potential of flavonoids to act as P-gp inhibitors, enabling increased absorption, brain penetration, inhibition of excretion and modulation of multi-drug resistance. There is an overview of the investigations on the feasibility and application of flavonoids as P-gp modulators for improved efficacy of anti-cancer drugs like taxanes, anthracyclines, epipodophyllotoxins, camptothecins and vinca alkaloids. In addition, the focus is on flavonoid-drug interactions and novel methods to improve cancer drug treatment by temporary inhibition of these systems. Various experimental models which could be used for investigation on P-gp mediated efflux are also briefly described.

\section{P-GP: STRUCTURE AND DISTRIBUTION}

P-gp is an adenosine triphosphatase (ATPase), energy-dependent membrane bound protein belonging to members of ATP binding cassette (ABC) transporters (15). It comprises of 1280 amino acids and is expressed as a single chain containing two homologous portions of equal length, each containing six transmembrane domains and two ATP binding regions separated by a flexible linker polypeptide region (Figure 1). The flexible secondary structure of the connector region is sufficient for the coordinate functioning of the two halves of P-gp, which is likely required for the proper interaction of the two ATP binding sites (16). 
Table 1. List of anti-cancer drugs known to be Pgp substrates (adoptrd from $6,13,14$ )

\begin{tabular}{|c|c|}
\hline Chemical Class & P-gp Substrates \\
\hline \multirow[t]{4}{*}{ Anthracyclines } & Doxorubicin \\
\hline & Daunorubicin \\
\hline & Epirubicin \\
\hline & Idarubicin \\
\hline \multirow[t]{4}{*}{ Vinca alkaloids } & Vincristine \\
\hline & Vinblastine \\
\hline & Vinorebline \\
\hline & Vindesine \\
\hline \multirow[t]{2}{*}{ Taxanes } & Paclitaxel \\
\hline & Docetaxel \\
\hline \multirow[t]{3}{*}{ Epipodophylloto } & \\
\hline & Etoposide \\
\hline & Teniposide \\
\hline \multirow[t]{3}{*}{ Camptothecins } & Topotecan \\
\hline & Irinotecan \\
\hline & SN-38 \\
\hline \multirow[t]{9}{*}{ Miscellaneous } & Mitoxantrone \\
\hline & Trimetrexate \\
\hline & Actinomycin D \\
\hline & Methotrexate \\
\hline & Colchicine \\
\hline & Tamoxifen \\
\hline & Imatinib \\
\hline & Mitomycin C \\
\hline & Amasacrine \\
\hline
\end{tabular}

ATP-binding domain(s) located in the cytosol side, are also known as nucleotide-binding folds (NBFs). The NBFs are located in the cytoplasm and they transfer the energy to transport the substrates across the membranes. Each ATPbinding domain contains three regions: Walker A, $\mathrm{B}$, and signature $\mathrm{C}$ motifs. Highly conserved Lys residue within the walker $\mathrm{A}$ motif of histadine permease is directly involved with the binding of ATP and a highly conserved Asp residue within the walker B motif serves to bind the Magnesium $(\mathrm{Mg} 2+)$ ion. Human P-gp requires both $(\mathrm{Mg} 2+)-$ ATP-binding and hydrolysis to function as a drug transporter (17). It has also been proposed that magnesium may play a role in stabilizing the ATP-binding site. Signature C motifs probably participate to accelerate ATP hydrolysis via chemical transition state interaction and are also suggested to be involved in the transduction of the energy of ATP hydrolysis to the conformational changes in the membrane integral domains required for translocation of the substrate (8).

Unlike the ATP-binding sites that are restricted to Walker A motifs of ATP-binding domains, many substrate binding sites have been identified throughout the transmembrane (TM) domain of P-gp. The major drug-binding sites reside in or near TM6 and TM12. In addition to this, TM1, TM4, TM10, and TM11 have drugbinding sites. Amino acids in TM1 are involved in the formation of a binding pocket that plays a role in determining the suitable substrate size for P-gp, whereas Glycine residues in TMs 2 and 3 are important in determining substrate specificity. The close proximity of TM2/ TM11 and TM5/TM8 indicates that these regions between the two halves must enclose the drug-binding pocket at the cytoplasmic side of P-gp. They may form the "hinges" required for conformational changes during the transport cycle $(4,18)$. In addition to the TM domains, intracellular loops and even ATP binding domains have drugbinding sites. Each of the two TM domains of Pgp consists of six long $\alpha$-helical segments. Five of the $\alpha$-helices from each TM domain are related by a pseudo-twofold symmetry, whereas the sixth breaks the symmetry. The two $\alpha$-helices positioned closest to the (pseudo) symmetry axis at the centre of the molecule appear to be kinked. P-gp has amino-and carboxyl terminals. Initially, it was believed that N-terminal ATP-binding domain contains all residues necessary to hydrolyze ATP without interacting with the Cterminal ATP-binding domain (19). But now it is believed that both the amino- and carboxylterminal ATP sites can hydrolyze ATP. However, there is no evidence that ATP can be hydrolyzed simultaneously by both sites (8).

\section{P-gp expression in normal tissues}

P-gp has been evidenced in several human normal tissues, including the liver, kidney, pancreas, and small and large intestine (20). Similarly, elevated mouse mdrl, mdr2 and mdr3 messenger ribo 
nucleic acid (mRNA) levels have been shown in kidney, liver and intestine, respectively (21). In all of these organs, P-gp is localized at the luminal surface of epithelial cells, suggesting that it may have a physiological role in the elimination of xenobiotics or some endogenous metabolites. Presence of P-gp in the placenta of the mice and in the adrenal cortex, suggests its role in physiological steroid secretion (22). P-gp is also expressed by endothelial cells at blood-tissue barrier sites, such as the blood-brain barrier and, thus, may protect the brain from circulating xenobiotics, including anticancer drugs (23). In addition, P-gp has been found to be functional in human hematopoietic stem cells, indicating its contribution to the chemoresistance of these cells. Some peripheral blood mononuclear cells, such as cytotoxic T lymphocytes and natural killer cells, also express P-gp, suggesting their involvement in cell mediated cytotoxicity. Immunohistochemical analysis using monoclonal antibody provided evidence for localization of P-gp in columnar epithelial cells of lower gastrointestinal tract (GIT), capillary endothelial cells of brain and testis, canalicular surface of hepatocytes and apical surface of proximal tubule in kidney. Due to selective distribution of P-gp at the drug entry and exit ports, it is speculated that P-gp could play a major physiological role in absorption, distribution and excretion of xenobiotics (Figure 2). Therefore, overall P-gp functions as a biochemical barrier for entry of xenobiotics and expels them from the organs into the systemic circulation (24).

\section{P-gp expression in cancer}

Numerous studies have been conducted during the last few years to analyze the expression of P-gp in solid tumors and haematological malignancies and to determine its clinical relevance. P-gp expression is usually high and constitutive in tumors that arise from tissues known to physiologically express the carrier, such as carcinoma of the colon, kidney, adrenal gland, pancreas and liver. Intermediate levels of P-gp expression have been observed at time of diagnosis in some neuroblastomas and soft tissue carcinomas and in some haematological malignancies. On the other hand, tumors of the lung, esophagus, stomach, ovary and breast, melanomas, lymphomas, multiple myelomas and some leukemias usually display initial low P-gp expression (26). However, some of these malignancies may display elevated levels of P-gp after chemotherapy. A higher incidence of P-gp expression after treatment has been demonstrated in breast tumors, acute myeloid leukemias, lymphomas and myelomas (27).

P-gp positivity in some cancers is associated with increased levels of other drug resistance markers such as Multi-drug resistance associated protein (MRP) and glutathione Stransferase pi expression (28). P-gp expression has been correlated with treatment failure and poor prognosis in several types of cancer, although not all studies are in agreement. A strong correlation of increased levels of MDR1 expression with relapse has been evidenced in pediatric soft tissue sarcomas, neuroblastoma and acute lymphoblastic leukemia (24). In contrast, Ino et al. have found that P-gp expression at initial presentation did not significantly influence the outcome of treatment in acute myeloid leukemia (29).

Despite the increasing number of reports demonstrating a correlation between P-gp positivity and treatment failure there is no absolute consensus on the clinical relevance of $\mathrm{P}$ gp expression. Further studies using a standardized method of P-gp determination in clinical samples are, therefore, needed to provide definite evidence of the involvement of P-gp in clinical drug resistance (24). For a long time, P-gp was believed to be the only protein capable of conferring MDR in mammalian tumor cells. However, several reports on human tumor cell lines displaying MDR in the absence of P-gp overexpression, together with studies that failed to detect P-gp in a variety of human tumors pointed to the existence of other MDR conferring proteins (30).

\section{MECHANISM OF P-GP MEDIATED EFFLUX}

P-gp mediated efflux is saturable, ATP dependent, osmotically sensitive transport that generates a concentration gradient. The first step in drug efflux is drug recognition by P-gp followed by ATP-binding and hydrolysis. The major drug binding sites reside in or near TM6, TM12, TM1, TM4, TM10, and TM11. There is the formation of a binding pocket which plays a role in determining the suitable substrate/ drug size for P-gp and therefore substrate specificity (31). 


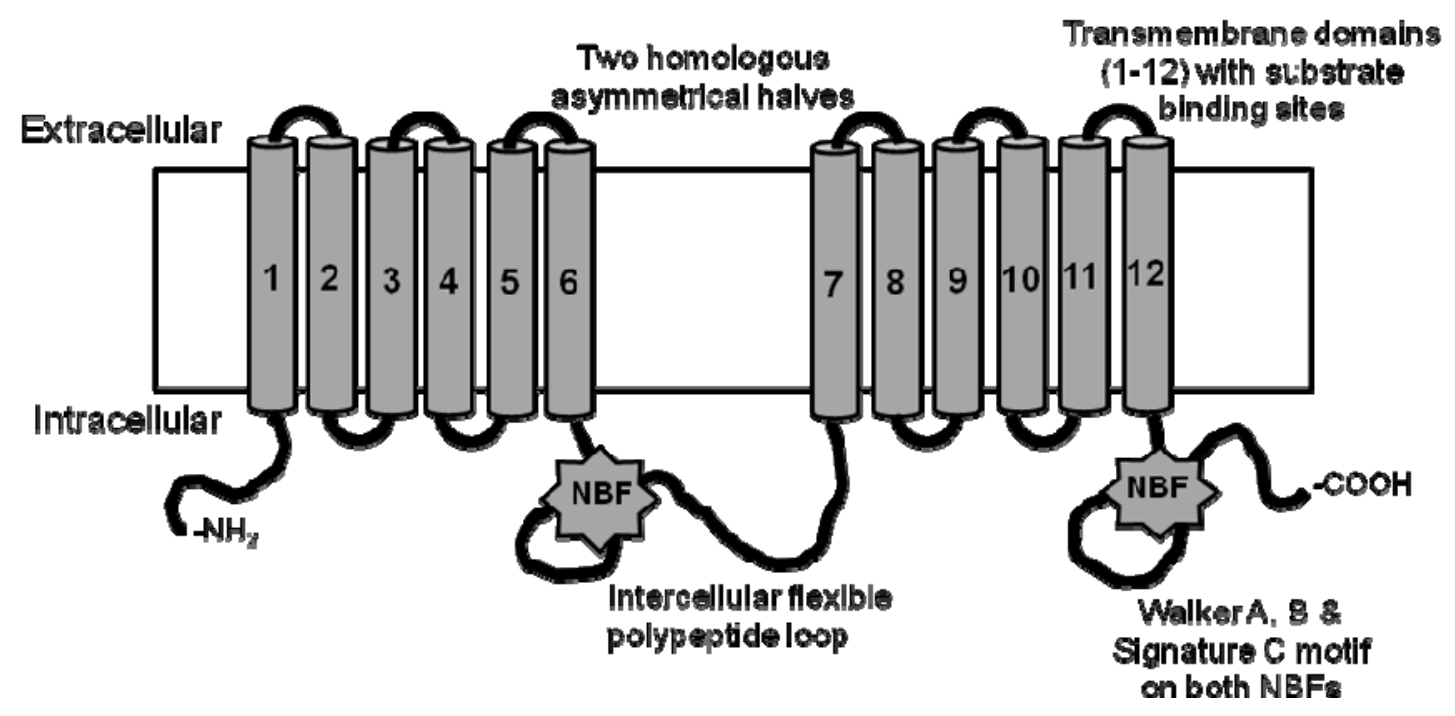

Figure 1. Structure of P-glycoprotein (Adoptef from 3)

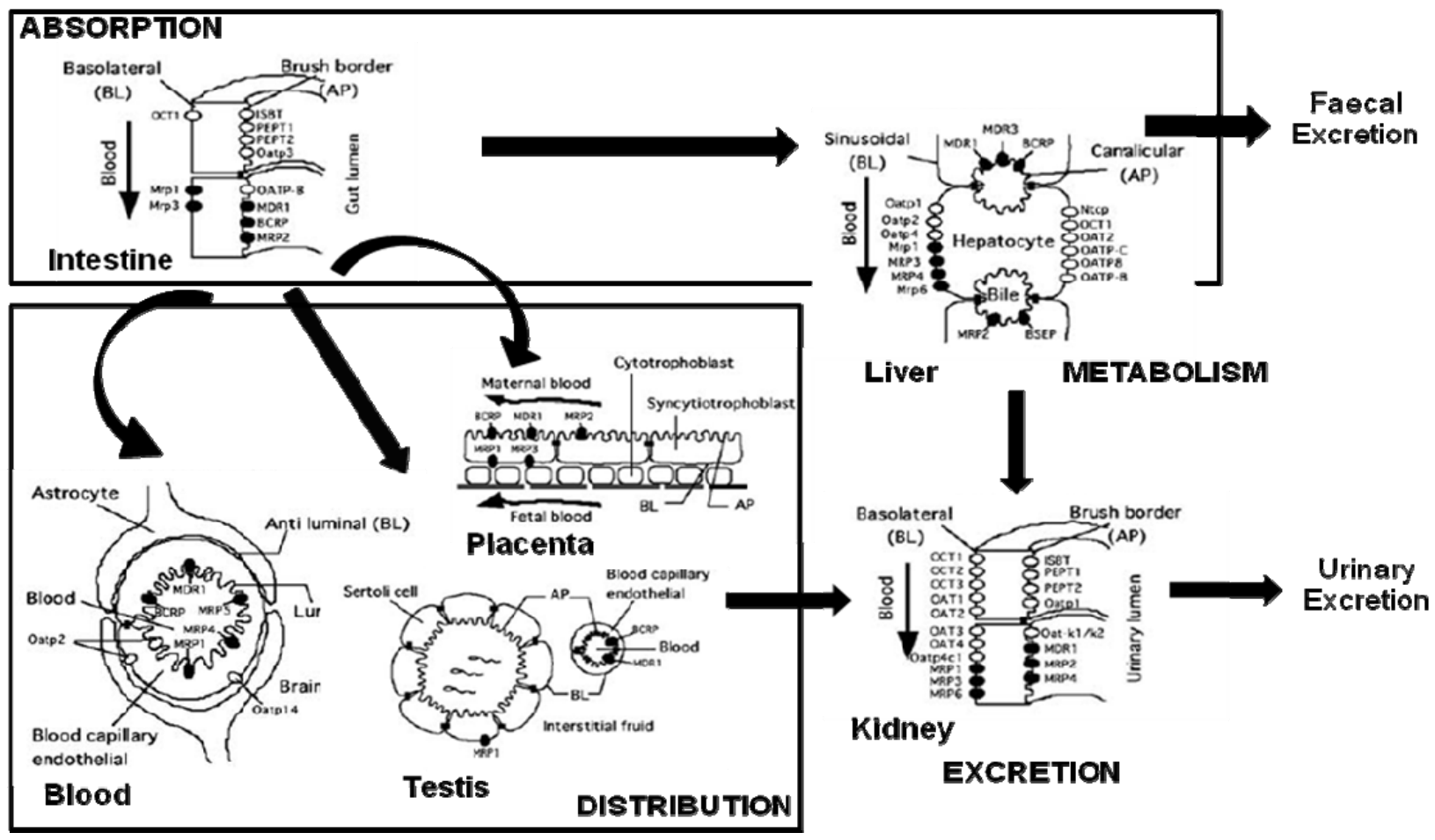

Figure 2. Diagram indicating occurrence of P-gp in various normal body tissues and how it can play part in deciding drug's pharmacokinetics. (i) Intestine, where it pumps the drug back into the GI lumen resulting in fecal excretion,(ii) Liver present in canalicular surface of hepatocytes to remove drug and metabolites from interior of cell (iii) Endothelial cells of blood brain barrier, preventing the entry of xenobiotics into brain, (iv) Proximal tubular membrane of kidney to pump drug into urine and (v) In certain hematological cells to put drug back into circulation. Adopted from 25. 
The energy released in this process is utilized to efflux substrate outside the cell membrane through central pore. Around 0.6-3 molecules of ATP are hydrolyzed for every molecule of the drug transported out of the cell (4). In contrast, the study by Sauna and Ambudkar (32) suggested that two ATP molecules are hydrolyzed for the transport of every substrate molecule; one in the transport of substrate and the other in causing conformational changes to reset the pump for the next catalytic cycle. The release of ADP from nucleotide binding site ends the first catalytic cycle followed by a conformational change that reduces affinity for both substrate and nucleotide (Figure 3). Further, the second catalytic cycle starts by hydrolysis of another molecule of ATP and released energy is utilized to reorient the protein to its native conformation. Subsequent release of ADP completes another catalytic cycle, bringing P-gp molecule back to the original state, where it again binds to both substrate and nucleotide to initiate the next cycle (33).

The mechanism of xenobiotic extrusion by P-gp has been described by various ways; however, the exact site of substrate interaction with the protein is not well resolved (18). The most popular models include pore model, flippase model and hydrophobic vacuum cleaner model (8). Among these hydrophobic vacuum cleaner model has gained wide acceptance according to which P-gp recognizes substrates embedded in the inner leaflet of plasma membrane and transport it through a protein channel. Its mechanism of action is described to be similar to a "hydrophobic vacuum cleaner" since the drugs are detected and expelled as they enter the plasma membrane (34). 'Hydrophobic' because most of the P-gp substrates have been found to be hydrophobic with a planar ring system and often carries a positive charge at physiological $\mathrm{pH}$. However uncharged, hydrophilic and others having planar ring system e.g. colchicine also are effluxed out suggesting some other mechanism. Change in electric potential and $\mathrm{pH}$ across membrane may also contribute to this process. Rosenberg et al. proposed that P-gp undergoes conformational changes on binding of nucleotide to the intracellular nucleotide-binding domains. Signature $\mathrm{C}$ motifs are probably suggested to be involved in the transduction of the energy of ATP hydrolysis to produce conformational changes in the membrane-integral domains required for translocation of the substrate (35).

According to "pore model", there is a major reorganization of the transmembrane domains throughout the entire depth of the membrane on binding of nucleotide. This restructuring opens the central "pore" along its length in a manner that allows access of hydrophobic drugs (or, substrates) directly from the lipid bilayer to the central pore of the transporter (36).

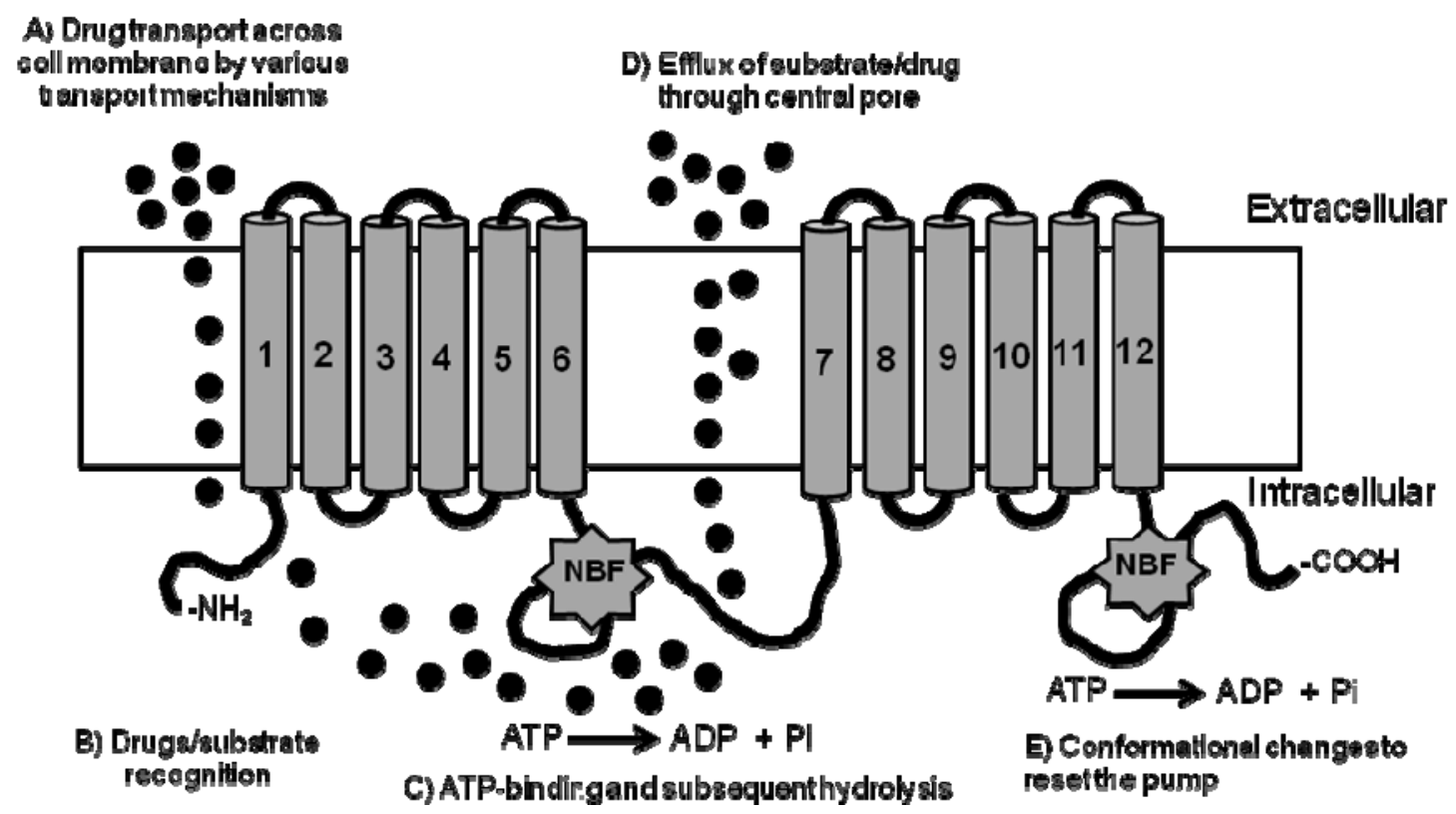

Figure 3. Mechanism of P-gp mediated efflux 
However, recently, it has been proposed that drug substrates first diffuse from the lipid bilayer into the drug-binding pocket through "gates" formed by TM segments at either end of the drug-binding pocket and then effluxes the substrate through the central pore of the transporter to outside the membrane (37). Another hypothesis is that the Pgp is essentially a "flippase" that detects drug within the inner leaflet of the membrane and "flips" it into the outer leaflet (from which it can diffuse away from the cell) or directly into the extracellular space. P-gp intercepts lipophilic drugs as they move through the lipid membrane and flips the drugs from inner leaflets to the outer leaflet and to extra cellular medium (6).

\section{P-GP INHIBITION}

The first report of the pharmacological reversal of MDR came from Tsuruo et al. in 1980s, who showed that the calcium channel blocker, verapamil, and the calmodulin antagonist, trifluoperazine, greatly potentiated the antiproliferative activity of vincristine and produced an increased cellular accumulation of vincristine in an MDR murine leukaemia cell line in vitro and in vivo (38). Since this original observation, many compounds have been shown to antagonise MDR in a variety of cell lines and in vivo tumour models. Subsequently, many P-gp inhibitors such as valspoder (PSC-833), dofequidar fumarate (MS-209), tariquidar (XR9576), and thiosemicarbazone derivative (NSC73306) have been developed that interact with P-gp and reverse Pgp-mediated drug resistance. P-gp inhibitors are classified into three generations based on their chronological development and specificity and/or affinity towards P-gp $(1,33)$.

\section{First generation P-gp inhibitors}

First-generation inhibitors are pharmacological compounds, which were developed and are used for other indications but have been shown to inhibit P-gp. Many agents of diverse structure and function that modulate P-gp have been identified. These include calcium channel blockers such as verapamil; immunosuppressants like cyclosporin $\mathrm{A}$; anti-hypertensives, reserpine, quinidine and yohimbine; and antiestrogens like tamoxifen and toremifene. Vincristine inhibited P-gp by $95 \%$ and was more potent than other anthracycline analogues tested (39). First generation compounds tend to be less potent, non-selective and their usage being limited by toxicity due to the high serum concentrations achieved with the dose that is required to inhibit P-gp. In addition, many of the first-generation chemosensitizers were themselves substrates for P-gp and competed with the co-administered substrates for efflux by the MDR pumps. As a result, high serum concentrations of the chemosensitizers were needed to produce sufficient intracellular concentrations. Clinical trials with first-generation MDR drugs failed due to these reasons and consequently, this prompted researchers and pharmaceutical industries to move in the direction of second and third-generation inhibitors which would specifically modulate P-gp (14).

\section{Second generation P-gp inhibitors}

Second-generation modulators constitute the agents that lack the pharmacological activity of the first-generation compounds and possess a higher P-gp affinity. Examples of agents belonging to this category include PSC 833 (nonimmunosuppresive analogues of cyclosporin A) and dexverapamil (R-isomer of verapamil lacking the cardiac effects), biricodar (VX-710), GF120918 and MS-209 (14, 33). Although these compounds were developed with a view to have less toxicity, still they retained some characteristics that limited their clinical usefulness. The affinity of second-generation MDR drugs towards P-gp was too low to produce significant inhibition in vivo at tolerable doses. Most of the second-generation chemosensitizers were also substrates for CYP 3A4 (40). As a result, the competition between anticancer agents and MDR modulators for CYP 3A4 activity resulted in unpredictable pharmacokinetic interactions affecting the metabolism and/or clearance mechanisms. This produced increased anticancer drug concentrations leading to unacceptable side effects, necessitating dose reductions down to sub-toxic levels (28). Furthermore, inhibition of non-target transporters by these compounds enhanced adverse effects of anticancer drugs (30).

\section{Third generation P-gp inhibitors}

Structure-activity relationships and combinatorial chemistry approaches have resulted in development of novel third-generation P-gp blockers, primarily with the purpose to improve the treatment of multidrug resistant tumours and to inhibit P-gp with high specificity and toxicity. They are neither metabolized by CYP $3 \mathrm{~A} 4$ and 
nor they alter the plasma pharmacokinetics of anticancer drugs. Modulators such as LY335979, OC144093 and XR9576 are identified to be highly potent (active in nano-molar ranges) and selective inhibitors of P-gp with a potency of about 10 -fold more than the first and secondgeneration inhibitors $(1,33)$. None of the thirdgeneration agents tested so far have caused clinically relevant alterations in the pharmacokinetics of the co-administered anticancer drugs. As a result, such compounds originating from various drug development programs offer significant improvements in cancer therapy and are currently undergoing clinical trials with various anticancer drugs in several types of cancer (40). Tariquidar (anthranilamide derivative) gave successful results in phase I and II studies with paclitaxel and vinorelbine in ovarian cancer, and phase III trials have already been initiated. R101933 and ONT-093 were shown to inhibit P-gp pump with no effect on the pharmacokinetics of docetaxel and paclitaxel. The cyclopropyldibenzosuberane modulator LY335979 developed by Eli Lilly Inc. was shown to competitively inhibit the binding of vinblastine to P-gp. GF-120918 (elacridar) was developed by Glaxosmithkline which inhibits P$\mathrm{gp}$ and Breast cancer resistance protein (BCRP) and shows no pharmacokinetic interactions with doxorubicin. Clinical trials using such P-gp inhibitors have shown an in vivo increased intracellular concentration of coadministered anticancer agents in P-gp-expressing tumor cells. Further studies with these new third-generation agents are ongoing with the aim for a longer survival in cancer patients. However, phase III trials of some of these agents have not been successful and no significant survival benefit of P-gp inhibition has yet been achieved $(30,40)$.

As an alternative, recently compounds belonging to categories of pharmaceutical excipients and herbal supplements are emerging as a different class of P-gp inhibitors (33, 41-44). Co-formulation with pharmaceutical excipients produce effects contribute to the improved bioavailability seen for P-gp substrates $(45,46)$. Although these "inert" pharmaceutical excipients appear to be a better choice from formulation perspective, they suffer from limitations of causing undesirable alterations in drug disposition resulting in serious adverse reactions (47).

Another class which is gaining rapid attention as P-gp modulators are herbal components $(44,48,49)$. They form ideal P-gp inhibitors since they are non-toxic and do not have any pharmacological activity of their own. The safety of herbs is ensured by the continuous and long history of usage in large amounts as a part of normal daily diet. They are this considered as perfect candidates for bioavailability enhancement, tissue-penetration (e.g. blood brain barrier), decreasing biliary excretion and multi-drug resistance modulating agents. Moreover, it is especially important to identify food components having such effects, since it will provide in-depth knowledge of fooddrug interactions, which could be utilized for beneficial effects. A list of compounds shown to have P-gp interacting property is depicted in table 2.

\section{HERBAL MODULATION OF P-GP}

The revival of scientific interest in herbal components has resulted in increased consumption of these compounds mainly as alternative or supplements to cancer therapy, posing a serious potential for herb-drug interactions. The first evidence of P-gp inhibition by such components came from the grapefruit juice interactions with numerous drugs (59). Since then there are frequent reports of pharmacokinetic interactions of herbs with drugs, causing either beneficial or harmful effects $(44,53)$. Combined use of herbs with drugs may mimic, increase, or reduce the effects of either component, resulting in herb-drug interactions (60). The herb-drug interactions can be hazardous if they cause increased drug levels reaching above toxic threshold. On the other side, these effects may be exploited beneficially to improve pharmacokinetics of co-administered drug (61). Altered pharmacokinetics (absorption, metabolism, distribution, and excretion) of drugs by herbs may thus provide an explanation for some interactions. However, the underlying mechanisms for the altered drug concentrations by concomitant herbs are always unknown. Increasing evidence from in vitro and in vivo studies indicated that the altered drug concentrations by co-administered herbs may be attributable to the induction or inhibition of hepatic and intestinal drug-metabolizing enzymes (CYPs), and drug transporters such as P-gp (6265). Consequently this has raised concerns regarding their potential P-gp mediated pharmacokinetic interaction with chemotherapeutic agents $(50,54,66)$. Therefore, it is important to identify potential modulators of P-gp from herbal medicines using in vitro and in 
vivo models using proper probe substrates (44). The inhibition of P-gp by herbal constituents may provide a novel approach for reversing multidrug resistance in tumor cells, whereas on the contrary the allosteric elevation of P-gp by some herbal constituents has implication for chemoprotective enhancement by herbal medicines. Certain natural flavonols (e.g., kaempferol, quercetin, and galangin) are potent stimulators of the P-gp mediated efflux of 7,12-dimethylbenz(a)anthracene (a carcinogen) (58, 67). The modulation of P-gp activity and expression by these herb constituents may result in altered absorption and bioavailability of drugs that are Pgp substrates. Accordingly, much effort is currently being expanded toward identifying natural compounds from plant origins that inhibit P-gp, reverse the MDR phenotype, and sensitize cancer cells to conventional chemotherapy without undesired toxicological effects $(51,58)$. Table 3 shows a compilation of various herbs and their effect on P-gp.

\section{FLAVONOIDS AS P-GP INHIBITORS}

Many of the plants appeared to be relatively nonspecific and exerted unwanted herb-drug interactions or interference with other physiological systems reducing their potential use in clinical settings. This stimulated the quest for relatively specific inhibitors and the interest in flavonoids as relatively specific inhibitors of P-gp transporter. Moreover, flavonoids are the most abundant polyphenols forming an integral component of our common diet.

They are particularly abundant in vegetables, fruits and plant-derived beverages such as wine and tea. The daily intake of total flavonoids from the average U.S. diet was estimated to be more than $1 \mathrm{~g}(68)$. In addition, a variety of flavonoid-containing dietary supplements and herbal products are now available in the market because of their proposed health-promoting activities, such as antioxidant, anticarcinogenic, anti-inflammatory, antiproliferative, antiangiogenic, and antiestrogenic (or estrogenic) effects and the lack of toxicity associated with this class of compounds $(68,69)$.

Flavonoids possess a chromane ring skeleton with an additional aromatic ring attached at position 2,3 or 4 (88). Based on different substitution and the oxidation status of ring $\mathrm{C}$, flavonoids can be classified into several subclasses including flavones, flavonols, flavonones, flavanols, isoflavones and chalcones (Table 4).

In foods, flavonoids are often present as $\beta$-glycosides of aglycones and methoxylated forms. Upon ingestion, flavonoid glycosides are deglycosylated and the aglycones are metabolized into glucuronide-, sulfate- and methoxylated conjugates. The concentrations required for flavonoids to produce a significant modulation of P-gp activity seem to be, in general, $10 \mu \mathrm{M}$ or higher, which appears to be achievable in the intestine after ingestion of food and dietary supplementation. For example, grapefruit juice contains $145-638 \mathrm{mg} / \mathrm{L}$ naringin (89), equivalent to $250-1100 \mu \mathrm{M}$, and orange juice contains 200 $450 \mathrm{mg} / \mathrm{L}$ hesperidin (90), equivalent to $330-740$ $\mu \mathrm{M}$. Although these flavonoid glycosides may not potently interact with P-gp, their corresponding aglycones released from these glycosides in the intestine could be present in high enough concentrations to inhibit intestinal P-gp, resulting in drug interactions. However, the main metabolites of flavonoids (glucuronides and sulfate conjugates) may not interact with P-gp because these metabolites are organic anions. So, systemic inhibition of P-gp by flavonoids or their metabolites may be, in general, insignificant after regular supplementation. Interaction could occur after administration of an extremely high dose, especially by i.v. injection (54).

Recent literature cites various examples for flavonoids as P-gp transport inhibitors affecting the bioavailability and uptake of anticancer drugs (Table 5). These include in vitro studies on the effect of flavonoids on intracellular accumulation of P-gp substrates using P-gp overexpressing cells or a variety of clinical and animal studies, especially those using P-gp knockout animals (54). For example, co-administration of quercetin and moxidectin subcutaneously increased moxidectin bioavailability in lambs (91); naringin can increase the oral bioavailability of quinine in rats (92); baicalein and its aglycone baicalein can both increase the oral bioavailability of cyclosporine in rats (93); flavones and quercetin can increase the oral bioavailability of paclitaxel in rats $(94,95)$ and quercetin can increase oral bioavailability of digoxin in pigs and resulted in a very serious toxicity (96). All these studies indicated that flavonoid-P-gp interactions could occur in vivo, resulting in pharmacokinetic interactions. 
Table 2. List of P-gp modulators belonging to different classes (adopted from 33, 40, 43-45, 47-58)

\begin{tabular}{|c|c|c|c|c|c|c|}
\hline \multicolumn{6}{|c|}{ P-gp Inhibitors } & \multirow[b]{3}{*}{ P-gp Inducers } \\
\hline \multirow[b]{2}{*}{ I Generation } & \multirow[b]{2}{*}{$\begin{array}{c}\text { II } \\
\text { Generation }\end{array}$} & \multicolumn{4}{|c|}{ III Generation } & \\
\hline & & $\begin{array}{l}\text { Synthetic } \\
\text { compounds }\end{array}$ & $\begin{array}{c}\text { Pharmaceutical } \\
\text { Excipients }\end{array}$ & $\begin{array}{l}\text { Herbs and } \\
\text { Fruits }\end{array}$ & $\begin{array}{c}\text { Herbal } \\
\text { Constituents }\end{array}$ & \\
\hline $\begin{array}{l}\text { Verapamil } \\
\text { Felodipine } \\
\text { Nifedipine } \\
\text { Diltiazem } \\
\text { Chlorpromazine } \\
\text { Quinidine } \\
\text { Cyclosporin A } \\
\text { Erythromycin } \\
\text { Flufenazine } \\
\text { Reserpine } \\
\text { Progesterone } \\
\text { Tamoxifen }\end{array}$ & $\begin{array}{l}\text { Dexverapamil } \\
\text { Gallopamil } \\
\text { PSC 833 } \\
\text { (Valspodar) } \\
\text { VX-710 } \\
\text { (Biricodar) } \\
\text { MS-209 } \\
\text { GF 120918 } \\
\text { Reversin } 121 \\
\text { Reversin } 125\end{array}$ & $\begin{array}{l}\text { LY } 335979 \\
\text { XR 9576 } \\
\text { (tariquidar) } \\
\text { OC 144- } \\
093 \\
\text { R } 101933 \\
\text { Mitotane } \\
\text { (NSC- } \\
\text { 38721) } \\
\text { Annamycin }\end{array}$ & $\begin{array}{l}\text { C8/C10Glycerol \& } \\
\text { PEG esters } \\
\text { Cremophor } \\
\text { Solutol HS-15 } \\
\text { Labrasol } \\
\text { Softigen } 767 \\
\text { Aconnon E } \\
\text { Sucrose esters } \\
\text { Sucrose monolaurate } \\
\text { Polysorbates } \\
\text { Tween } 80 \\
\text { Tween 20 } \\
\text { Tocopherol esters } \\
\alpha \text {-tocopheryl-PEG- } \\
\text { 1000-succinate } \\
\text { (TPGS) } \\
\text { Polymers } \\
\text { Pluronic block } \\
\text { copolymers } \\
\text { (poloxamers) } \\
\text { Poly-(ethyleneoxide) } \\
\text { / poly- } \\
\text { (propyleneoxide) } \\
\text { block copolymers } \\
\text { Amphiphilic Diblock } \\
\text { Copolymers } \\
\text { Methoxypolyethylene } \\
\text { glycol-block- } \\
\text { polycaprolactone }\end{array}$ & $\begin{array}{l}\text { Grapefruit } \\
\text { Orange } \\
\text { Apricot } \\
\text { Mint } \\
\text { Strawberry } \\
\text { Green tea } \\
\text { Rosemary } \\
\text { extract } \\
\text { Curcumin } \\
\text { Garlic } \\
\text { Milk Thistle } \\
\text { Ginseng } \\
\text { Piper nigrum } \\
\text { Ginko } \\
\text { Onion } \\
\text { African potato }\end{array}$ & $\begin{array}{l}\text { Flavonoids } \\
\text { Quercetin } \\
\text { Isoquercitrin } \\
\text { Spiraeoside } \\
\text { Rutin } \\
\text { Kaempferol } \\
\text { Naringenin } \\
\text { Naringin } \\
\text { Kaempferol } \\
\text { Biochanin A } \\
\text { Morin } \\
\text { Silymarin } \\
\text { Genistein } \\
\text { Bergamottin } \\
\text { Catechin } \\
\text { Hesperitin } \\
\text { Phloretin } \\
\text { Tangeretin } \\
\text { Monoterpenoids } \\
\text { (R)-(+)-citronellal } \\
\text { (S)-(-)-beta- } \\
\text { citronellol }\end{array}$ & $\begin{array}{l}\text { Adriamycin } \\
\text { Daunomycin } \\
\text { Mitoxantrone } \\
\text { Dexamethasone } \\
\text { Cyclosporin A } \\
\text { St. John's wort }\end{array}$ \\
\hline
\end{tabular}

Considering this accumulating evidence for flavonoid-drug interactions from clinical and animal studies, and non-requirement of Food and Drug Administration (FDA) approval for marketing of herbal supplements demand a careful evaluation of the interaction regarding molecular mechanisms determining drug disposition including absorption, distribution, metabolism and elimination.

\section{Mechanism behind flavonoid mediated P-gp inhibition}

In general, P-gp can be inhibited by more than one mechanism. There could be blockade of drug binding site either competitively, non-competitive or allosterically (8); interference with the ATP hydrolysis process $(32,36)$; alteration in integrity of cell membrane lipids (115) or decrease in P-gp expression (116). Drugs such as cyclosporine-A inhibit transport function by interfering with both substrate recognition and ATP hydrolysis. Whereas, few others like cis(Z)flupentixol (a thioxanthene derivative) prevent substrate translocation and dissociation due to allosterical changes produced in drug transporter (117). Compounds inhibiting ATP hydrolysis could serve as better inhibitors, since they are unlikely to be transported by P-gp, and these kinds of agents require low dose which is achievable at target site. Since none of the inhibitors known till now have been found to interact with the nucleotide binding sites to interfere the P-gp ATPase catalytic cycle, further research would provide newer and better inhibitors with potent and specific activity.

The mechanism for the herbal modulation of MDR1 gene is largely undetermined. Some 
herbal constituents (e.g., hyperforin and kava) were shown to activate Pregnane $\mathrm{X}$ receptor (PXR) (118) whereas others can upregulate or downregulate MDR1 gene expression (55). The underlying mechanisms by which herbal constituents, particularly flavonoids, alter P-gp mediated cellular efflux, is elucidated by examining passive permeability, P-gp expression, P-gp ATPase activity, and studying direct binding using the photoaffinity labels such as $\left[{ }^{3} \mathrm{H}\right]$ azidopine (80) (Figure 4). Some flavonoids and P-gp modulators have been shown to be able to change membrane lipid packing order and thus change membrane fluidity or permeability (119). So, it is possible that the observed effects of flavonoids on drug accumulation could be due to their nonspecific interaction with the cell membrane, resulting in increased passive membrane permeability (120). Alternately, flavonoid-induced decrease in P-gp expression in P-gp positive cells could be another possibility. Pgp has been demonstrated to be an ATP dependent carrier and many P-gp substrates and modulators have been shown to interact with P-gp ATPase activity causing both stimulation and inhibition. For example, the P-gp inhibitor verapamil has been reported to be one of the best stimulators of P-gp ATPase (121).

Thus, one potential mechanism responsible for the flavonoid inhibition of $\mathrm{P}$-gp mediated efflux may be the inhibition of P-gp ATPase by interacting directly with the vicinal ATP-binding site (122).

An additional way to understand the interaction of flavonoids with P-gp and its substrate binding, is to investigate the effects of flavonoids on $\left[{ }^{3} \mathrm{H}\right]$ azidopine photoaffinity labeling of P-gp. The inhibition of $\left[{ }^{3} \mathrm{H}\right]$ azidopine photoaffinity labeling of P-gp has been commonly used to indicate direct interaction with P-gp substrate binding (107). Both P-gp substrates and modulators such as vinblastine and verapamil have been shown to inhibit azidopine photoaffinity labeling of P-gp (123). In addition, they may interact with the steroid-binding site and substrate-binding site (80). The latter process involves either competitive binding to the substrate-binding site or interaction with other drug binding sites causing altered molecular conformation.

It has been shown that flavonoids genistein, epicatechin gallate, catechin gallate, epigallocatechin gallate and silymarin can inhibit the labeling of P-gp with its photoactive substrates $(79,80,107)$, indicating these flavonoids may directly bind to the P-gp substrate binding site.

In addition, flavonoids have also been shown to directly interact with the purified recombinant C-terminal nucleotide-binding domain from mouse P-gp (NBD2), and this binding domain may overlap with the ATP binding site and vicinal steroid binding site (124). Different flavonoids may also interact with P-gp differently, since opposite effects on P-gp ATPase activity has been observed for different flavonoids (80).

\section{Structural activity relationship (SAR) for flavonoid-P-gp interaction}

The SAR for flavonoid-P-gp interaction has been extensively studied by evaluating the binding affinity of different flavonoids with mouse NBD2 and reviewed by Boumendjel et al. (122). Although most of the compounds inhibit P-gp function by blocking drug binding sites, presence of multiple binding sites complicate understanding as well as hinder developing a true, conclusive SAR for substrates or inhibitors. In general, the presence of the 5-hydroxyl group, the 3-hydroxyl group and the 2, 3-double bond appears to be important for potent flavonoidNBD2 interaction. In addition, isoflavonoids with ring $B$ branched at position 3 instead of 2 have lower P-gp interaction activity (125).

Contradictory results have been reported concerning the MDR modulating activity of some natural flavonoid polyphenols, such as kaempferol, quercetin, and genistein. On one hand, Yeh and co-researchers showed that flavonols (such as kaempferol and quercetin) stimulated the P-gp mediated efflux of 7, 12 dimethylbenz $[a]$ - anthracene and doxorubicin $(126,127)$ as evident by an increase in doxorubicin resistance in two different MDR cell lines. In contrast, Scambia et al. reported that quercetin inhibited rhodamine-123 efflux and decreased doxorubicin resistance (106). Moreover, Shapiro and Ling, using a reconstituted P-gp system, showed that quercetin inhibited P-gp mediated transport of the fluorescent probe Hoechst 33342, at least in part by inhibiting P-gp ATPase activity (121). Keeping this in view, Ferte et al. synthesized and evaluated the MDRmodulating activity of flavonoid derivatives containing an $N$-benzylpiperazine side chain. These new derivatives were designed with the aim to both introduce basic nitrogen and to increase their lipophilic properties (128). 
Table 3. P-gp mediated herb interactions with anti-cancer drugs

\begin{tabular}{|c|c|c|c|c|c|}
\hline Source & $\begin{array}{l}\text { Herbal } \\
\text { Constituents }\end{array}$ & $\begin{array}{l}\text { Anti-cancer } \\
\text { drug }\end{array}$ & Model & Pharmacological outcome & References \\
\hline \multirow{2}{*}{ Curcuma longa } & \multirow[b]{2}{*}{ Curcumin } & Rhodamine-123 & $\begin{array}{l}\text { Primary cultures of } \\
\text { rat hepatocytes }\end{array}$ & $\begin{array}{l}\text { Curcumin inhibited } \\
\text { Rhodamine-123 efflux }\end{array}$ & (70) \\
\hline & & Vinblastine & $\begin{array}{l}\text { Drug-resistant KB- } \\
\text { V1 cells }\end{array}$ & $\begin{array}{l}\text { Increased sensitivity to } \\
\text { vinblastine }\end{array}$ & (71) \\
\hline $\begin{array}{l}\text { Garlic (Allium } \\
\text { Sativum) }\end{array}$ & $\begin{array}{l}\text { Sulfur-containing } \\
\text { compounds, } \\
\text { numerous } \\
\text { flavonoids/isoflavo } \\
\text { noids (such as } \\
\text { nobiletin, } \\
\text { quercetin, rutin, } \\
\text { and tangeretin) }\end{array}$ & NA & $\begin{array}{l}\text { Recombinant human } \\
\text { P-gp membranes }\end{array}$ & Inhibit the activities of Pgp & $(72)$ \\
\hline $\begin{array}{l}\text { Ginseng (Panax } \\
\text { Ginseng) }\end{array}$ & Ginsenosides & $\begin{array}{l}\text { Rhodamine } \\
123, \\
\text { vinblastine, } \\
\text { doxorubicin }\end{array}$ & $\begin{array}{l}\text { Multidrug-resistant } \\
\text { KBV20C cells }\end{array}$ & $\begin{array}{l}\text { Ginsenoside } \operatorname{Rg} 3 \text { promoted } \\
\text { accumulation of rhodamine } \\
123 \text {, inhibited vinblastine } \\
\text { efflux, and reversed the } \\
\text { resistance to doxorubicin } \\
\text { and vincristine in }\end{array}$ & (73) \\
\hline Grapefruit Juice & Flavonoids & $\begin{array}{l}\text { Rhodamine } \\
123, \\
\text { vinblastine, } \\
\text { doxorubicin }\end{array}$ & Caco- 2 cells & Inhibit drug uptake & $(74-77)$ \\
\hline \multirow[t]{2}{*}{$\begin{array}{l}\text { Green tea } \\
\text { (Camellia } \\
\text { sinensis) }\end{array}$} & \multirow[t]{2}{*}{$\begin{array}{l}\text { Catechins } \\
\text { (flavanols) }\end{array}$} & Doxorubicin & $\begin{array}{l}\text { Mice bearing } \\
\text { doxorubicin- } \\
\text { resistant P388 } \\
\text { leukemia }\end{array}$ & Increased the efficacy & (78) \\
\hline & & Vinblastine & $\mathrm{CH}^{\mathrm{R}} \mathrm{C} 5$ cells & Potentiated the cytotoxicity & (79) \\
\hline $\begin{array}{l}\text { Milk Thistle } \\
\text { (Silybum } \\
\text { marianum) }\end{array}$ & $\begin{array}{l}\text { Flavonolignans } \\
\text { (Silymarin) }\end{array}$ & Daunomycin & P-gp positive cells & $\begin{array}{l}\text { Increased daunomycin } \\
\text { accumulation }\end{array}$ & (80) \\
\hline Piper nigrum & Piperine & Cyclosporine & Caco- 2 cells & Inhibited drug transport & (81) \\
\hline \multirow{3}{*}{$\begin{array}{l}\text { St. John's wort } \\
\text { (Hypericum } \\
\text { perforatum }\end{array}$} & \multirow{3}{*}{$\begin{array}{l}\text { Hyperforin and } \\
\text { hypericin }\end{array}$} & Cyclosporin & $\begin{array}{l}\text { LS-180 intestinal } \\
\text { carcinoma cells; } \\
\text { rats; healthy } \\
\text { volunteers }\end{array}$ & $\begin{array}{l}\text { Induces intestinal Pgp in } \\
\text { vitro and in vivo }\end{array}$ & $(82-84)$ \\
\hline & & Irinotecan & Healthy volunteers & $\begin{array}{l}\text { Increased SN-38 plasma } \\
\text { concentrations } \\
\text { Ameliorated the } \\
\text { gastrointestinal } \\
\text { and hematological }\end{array}$ & (85) \\
\hline & & Irinotecan & Rats & $\begin{array}{l}\text { toxicities of irinotecan } \\
\text { along with significant } \\
\text { alterations in } \\
\text { pharmacokinetics of } \\
\text { irinotecan and SN-38 }\end{array}$ & (86) \\
\hline $\begin{array}{l}\text { Rosemary } \\
\text { (Rosemarinus } \\
\text { officinalis } \\
\text { Labiatae) }\end{array}$ & $\begin{array}{l}\text { Methanol-extracted } \\
\text { fraction }\end{array}$ & $\begin{array}{l}\text { Doxorubicin } \\
\text { and vinblastine }\end{array}$ & $\begin{array}{l}\text { Drug-resistant P-gp } \\
\text { expressing MCF-7 } \\
\text { cells }\end{array}$ & $\begin{array}{l}\text { Increased intracellular drug } \\
\text { accumulation }\end{array}$ & $(87)$ \\
\hline
\end{tabular}


A survey on MDR modulators concluded that this last criterion was frequently met by using a piperazine unit (128-131).

Isoflavones have been described as inactive on P-gp mediated MDR (132). Genistein (an isoflavone) was initially suggested to be inactive on P-gp mediated MDR, (132) but Castro et al. challenged this conclusion (107). Chalcones, flavones, and flavonols have been demonstrated to possess MDR reversing activity through high affinity binding with P-gp $(106,121$, 126). Studies on SAR compiled by Hadjeri et al. (133) on chalcones, flavones, and flavonols conclude that a hydroxyl group on position 5 (position 6' in chalcones) is important. 5-OH methylation leads to slightly less active compounds.

The hydroxyl loses its acidic properties because of the chelating effect induced by the adjacent carbonyl group, and therefore does not affect the activity which can be decreased by the presence of acidic groups. Hydroxylation on position 7 (position 4' in chalcones) was deleterious for activity, probably due to the acidic group influence, whereas methoxylation was slightly beneficial. The 2,3 double bond (the $\alpha, \beta$ double bond in chalcones) and the carbonyl group are also essential for MDR modulation $(122,124$, 133, 134).

\section{Quercetin mediated inhibition of P-gp}

Quercetin is the most predominant flavonoid in the human diet. Based on epidemiological studies in the U.S., Europe, and Asia, the daily dietary intake of quercetin is estimated to be in the range of 4 to $68 \mathrm{mg}$ which can be as high as several hundred $\mathrm{mg}$ in dietary supplement and several grams in anticancer therapy (96). Quercetin is nontoxic and displays a variety of biological actions such as antioxidation, antivirus, antiulcer, antiallergic, and anticancer, etc. Currently, it is in clinical trial as an anticancer therapy and is a potential drug of the future (101). It was reported that quercetin could competitively inhibit the members of MDR family, P-gp, MRP1 and BCRP $(106,135,136)$, and the metabolizing enzyme, CYP3A4 $(137,138)$.

Low concentrations of quercetin have indirectly activated the transport of vincristine by enhancing the phosphorylation and hence activity of P-gp, whereas high concentrations of quercetin inhibit P-gp (98).
Dupuy et al. (91) reported that the AUC and plasma concentration of moxidectin (a substrate for P-gp and CYP3A) increased when used concomitantly with $10 \mathrm{mg} / \mathrm{kg}$ of quercetin in lambs. The bioavailability of diltiazem pretreated with quercetin is increased significantly compared with the control, but not by co-administration of quercetin (102). The relative bioavailability of paclitaxel after administration of the prodrug to rats pretreated with quercetin was 1.25 to 2.02 fold higher than the prodrug control.

The Absolute bioavailability of paclitaxel was increased significantly by quercetin from 8.0 to 10.1 and $16.2 \%$ (95). Based on in vitro evidence, quercetin is an inhibitor of CYP $3 \mathrm{~A} 4$ and P-gp, and thus is likely to enhance the oral bioavailability of cyclosporin, a known substrate of CYP3A4/P-gp.

However, unexpectedly, in vivo results indicated that quercetin significantly decreased cyclosporin oral bioavailability, suggesting that the effect of quercetin on the fate of cyclosporin cannot be attributed to its modulation of CYP3A4 or P-gp. The in vitro evidence could therefore not be extrapolated to the in vivo effects of quercetin (139).

The explanation for controversial observations made regarding quercetin by various researchers $(106,121,126,127)$ is largely unknown.

It has been proposed that P-gp possesses two positively cooperative sites for drug binding; the $\mathrm{H}$ site preferring Hoechst 33342 to rhodamine 123 and the $\mathrm{R}$ site preferring rodamine 123 to Hoechst 33342. Binding to one of the sites results in stimulation of the transport of substrate that binds to the other site (34).

Quercetin preferentially binds to the $\mathrm{H}$ site, since it inhibited the transport of Hoechst 33342 and causes stimulation of the transport of rhodamine 123 (140). However, opposite effects on P-gp mediated transport have also been observed when the same model substrate was used $(106,126)$, thus other factors responsible for these inconsistent observations need to be identified (54).

\section{APPLICATIONS OF FLAVONOID MEDIATED P-GP INHIBITION IN CANCER THERAPY}

Several beneficial properties have been attributed to flavonoids including antioxidant, antiinflammatory, and anticarcinogenic effects. 
Table 4. Various classes of flavonoids, basic structure and their examples (adopted frm 50, 88)
Class of Flavonoid
Structure
Examples

Chalcones<smiles>O=C(/C=C/c1ccccc1)c1ccccc1</smiles>

Flavan-3-ols<smiles>OC1Cc2ccccc2OC1c1ccccc1</smiles>

Flavanones<smiles>O=C1CC(c2ccccc2)Oc2ccccc21</smiles>

Flavones<smiles>O=c1cc(-c2ccccc2)oc2ccccc12</smiles>

Flavonols<smiles>O=c1c(O)c(-c2ccccc2)oc2ccccc12</smiles>

Isoflavones<smiles>O=c1c(-c2ccccc2)coc2ccccc12</smiles>

Flavanolols<smiles>O=c1c(O)c(C2=CCCC=C2)oc2cc(O)cc(O)c12</smiles>

Phloretin

Acacetin, catechin, epi-catechin, epigallocatechin

Naringenin, naringin, hesperitin, eriodictoyl, hesperidin, pinocembrin, likvirtin

Apigenin, Luteolin, nobiletin, rpoifolin, tangeretin, flavone, baicalein, chrysin, techtochrysin, diosmetin, diosmin

Isoquercetrin, kaemferol, morin, rutin, myricetin, quercetin, quercetrin, myricitrin, spiraeocide, galangin, robinin, kaempferide, fisetin, rhamnetin

Genistein, daidzin

Silibinin, silymarin, taxifolin, pinocembrin
One important mechanism by which flavonoids exert their in vivo chemopreventive effects is through their inhibition of efflux transporters and metabolizing enzymes, such as CYP. Flavonoid and its derivatives possessing P-gp inhibitory effects may become candidates of effective agents in cancer chemotherapy. Following sections discuss the applications of flavonoids achieved via inhibition of drug transporter, P-gp.

\section{Pharmacokinetics optimization of anti-cancer drugs using flavonoids}

The use of P-gp inhibitors for modulating pharmacokinetics was initiated by studies which showed that patients receiving intravenous cyclosporin (P-gp inhibitor) prior to or together with the anti-cancer drugs had higher blood levels and exhibited the expected toxicity at substantially lower dosage levels. 
Table 5. Overview of literature on the effect of flavonoids on cellular accumulation, transport or bioavailability of various anti-cancer drugs. ADM-Adriamycin; SN-38- 7-ethyl 10-hydroxy camptothecin; $\mathrm{SD}$ - Sprague dawley; $\mathrm{K}_{\mathrm{a}}$ - absorption constant; $\mathrm{C}_{\max }$ - maximum plasma concentration; $\mathrm{t}_{1 / 2}$ - half life.

\begin{tabular}{lll} 
Flavanoid & P-gp substrate & $\begin{array}{l}\text { Model / Experimental } \\
\text { methods }\end{array}$ \\
\hline $\begin{array}{l}\text { Biochanin } \\
\begin{array}{l}\text { A, morin, phloretin, } \\
\text { and silymarin }\end{array}\end{array}$ & Doxorubicin & $\begin{array}{l}\text { MCF-7 and MDA435/LCC6 } \\
\text { cells, P-gp ATPase activity, }\end{array}$ \\
{$\left[\begin{array}{l}\left.{ }^{3} \mathrm{H}\right] \mathrm{azidopine} \text { photoaffinity } \\
\text { labeling }\end{array}\right.$}
\end{tabular}

Quercetin, morin and their ether derivatives

$\left[{ }^{3} \mathrm{H}\right]$ vincristine $\quad$ K562 and K562/ADM

Nobiletin, tangeretin and $3,30,40,5,6,7,8-$ heptamethoxyflavone Quercetin, chrysin, flavon, hesperetin, naringenin Kaempferol, galangin or quercetin

Biochanin A, morin, phloretin, silymarin

3,5,6,7,8,3,4-

Heptamethoxyflavone, nobiletin, and tangeretin, and flavone

Flavone

Quercetin

Kaempferol

Quercetin

Naringin

GF120918

(-)-Epigallocatechin (EGC), (-)epicatechin gallate (ECG), and (-)epigallocatechin gallate (EGCG)

Tangeretin, HeptaMethoxyFlavon $\left[{ }^{3} \mathrm{H}\right]$ vinblastine e (HMF) \& nobiletin

Vincristine

K562/ADM

Vincristine

MBEC4 cells and ddY mice

Doxorubicin

Daunomycin \& doxorubicin

Cultures rat hepatocytes

Multidrug resistant human breast cancer cell lines MCF7 and MDA435/L

$\left[{ }^{3} \mathrm{H}\right]$ vincristine

K562/ADM

Female SD rats

Tamoxifen

Male rats

Paclitaxel and its prodrug Paclitaxel and its prodrug

Colchicine, quercetin

Male SD rats

Male SD rats

In vitro (ECV304/C6 coculture) and in situ (rat) models

P-gp over-expressing KB-C2 cells

Caco-2 cells
Effect

Reference

Inhibit P-gp-mediated drug efflux; biochanin A and silymarin can potentiate doxorubicin cytotoxicity in Pgp positive cells

Pentamethylquercetin, pentaallylquercetin and pentaethylmorin remarkably increased the drug uptake

Increased drug uptake

Increased drug uptake in cells and enhanced brain-to-plasma concentration ratio in mice

Reduced drug retention with increase in its efflux Increased $\left[{ }^{3} \mathrm{H}\right]$ Daunomycin accumulation \& potentiated doxorubicin cytotoxicity

Increased the uptake of $\left[{ }^{3} \mathrm{H}\right]$ vincristine

AUC, $\mathrm{K}_{\mathrm{a}}, \mathrm{C}_{\max }$ increased and $\mathrm{T}_{1 / 2}$ prolonged

AUC, $\mathrm{K}_{\mathrm{a}}, \mathrm{C}_{\max }$ increased

AUC, Cmax, F increased

AUC, $\mathrm{K}_{\mathrm{a}}, \mathrm{C}_{\max }$ increased and $\mathrm{T}_{1 / 2}$ prolonged

AUC, $\mathrm{K}_{\mathrm{a}}, \mathrm{C}_{\max }$ increased and $\mathrm{T}_{1 / 2}$ prolonged Increased quercetin and colchicine permeation across blood brain barrier

Increased drug accumulation in the order $\mathrm{EGC}<\mathrm{ECG}<$ EGCG

Order of P-gp inhibitory potency tangeretin $>$ HMF $>$ nobiletin. 
Table 5. Continued

\begin{tabular}{|c|c|c|c|c|}
\hline Green tea polyphenols & Vinblastine & $\begin{array}{l}\text { Multidrug-resistant cell line } \\
\mathrm{CH}(\mathrm{R}) \mathrm{C} 5\end{array}$ & Potentiates the cytotoxicity & (79) \\
\hline Quercetin & Adriamycin & $\begin{array}{l}\text { MCF-7 ADR-resistant } \\
\text { human breast cancer cells }\end{array}$ & Reduced P-gp expression & (106) \\
\hline Genistein & $\begin{array}{l}\text { Rhodamine } 123 \\
\text { and daunorubicin }\end{array}$ & P-gp expressing cells & $\begin{array}{l}\text { Elevation in intracellular drug } \\
\text { accumulation }\end{array}$ & (107) \\
\hline $\begin{array}{l}\text { 6',7'- } \\
\text { Dihydroxybergamottin }\end{array}$ & Cyclosporin & P-gp expressing cells & $\begin{array}{l}\text { Did not inhibit P-gp at } \\
\text { concentrations up to } 50 \mathrm{uM}\end{array}$ & (108) \\
\hline $\begin{array}{l}7,3^{\prime}, 4^{\prime}- \\
\text { trimethoxyflavone }\end{array}$ & Paclitaxel & Caco- 2 cells & $\begin{array}{l}\text { Increased the AP-to-BL } \\
\text { transport of paclitaxel }\end{array}$ & (109) \\
\hline Quercetin & $\mathrm{SN}-38$ & Plasma membrane vesicles & $\begin{array}{l}\text { Quercetin was found to be the } \\
\text { strongest } \\
\text { inhibitor }(\mathrm{Ki}=0.28 \\
\text { microM) }\end{array}$ & (110) \\
\hline $\begin{array}{l}\text { Grape fruit juice (GFJ) } \\
\text { extracts }\end{array}$ & {$\left[{ }^{3} \mathrm{H}\right]$ Vinblastine } & Caco-2 cells & $\begin{array}{l}\mathrm{P}_{\text {app A-B }} \text { increased in the order of } \\
\text { the ethyl acetate }>\text { diethyl } \\
\text { ether }>\text { methylene chloride } \\
\text { extracts of GFJ }\end{array}$ & (76) \\
\hline Genistein & Paclitaxel & Male SD rats & $\begin{array}{l}\text { AUC, Cmax increased and CL } \\
\text { decreased }\end{array}$ & (111) \\
\hline Quercetin & Irinotecan, SN-38 & $\begin{array}{l}\text { Caco- } 2 \text { cells, Female wistar } \\
\text { rats }\end{array}$ & $\begin{array}{l}\text { Inhibit P-gp mediated drug } \\
\text { efflux; AUC of irinotecan and } \\
\text { SN-38 increased in plasma and } \\
\text { decreased in bile }\end{array}$ & (112) \\
\hline $\begin{array}{l}\text { (-)-epigallocatechin-3- } \\
\text { gallate }\end{array}$ & Irinotecan, SN-38 & Male SD rats & $\begin{array}{l}\text { AUC of irinotecan and } \mathrm{SN}-38 \\
\text { increased in plasma and } \\
\text { decreased in bile }\end{array}$ & (113) \\
\hline $\begin{array}{l}\text { Flavonols (quercetin } \\
\text { and kaempferol) and } \\
\text { isoflavones (genistein } \\
\text { and daidzein) }\end{array}$ & $\begin{array}{l}\text { Vinblastine and } \\
\text { paclitaxel }\end{array}$ & MDR KB-V1 cells & $\begin{array}{l}\text { Reduced P-gp expression and } \\
\text { function }\end{array}$ & (114) \\
\hline
\end{tabular}

In fact, clinical trials have been conducted to study the effects of cyclosporin on the pharmacokinetics and toxicities of paclitaxel, doxorubicin and etoposide (141-143). These studies were however limited to intravenous use of P-gp inhibitors and did not describe about the oral route. Presence of P-gp in the mucosal cells of the intestine indicates that oral administration of P-gp suppressing agents could improve the bioavailability of the orally unavailable agents (142, 144). Co-administration of a P-gp modulator usually elevate plasma concentrations of an anticancer drug by interfering its clearance or inhibiting its metabolism and excretion, thus leading to unacceptable toxicity that necessitates chemotherapy dose reductions in clinical trials, down to pharmacologically ineffective levels. Following sections present case studies of various anti-cancer drugs whose pharmacokinetics have been affected by P-gp modulation. The specific examples of drugs are illustrated in detail in the respective section. 


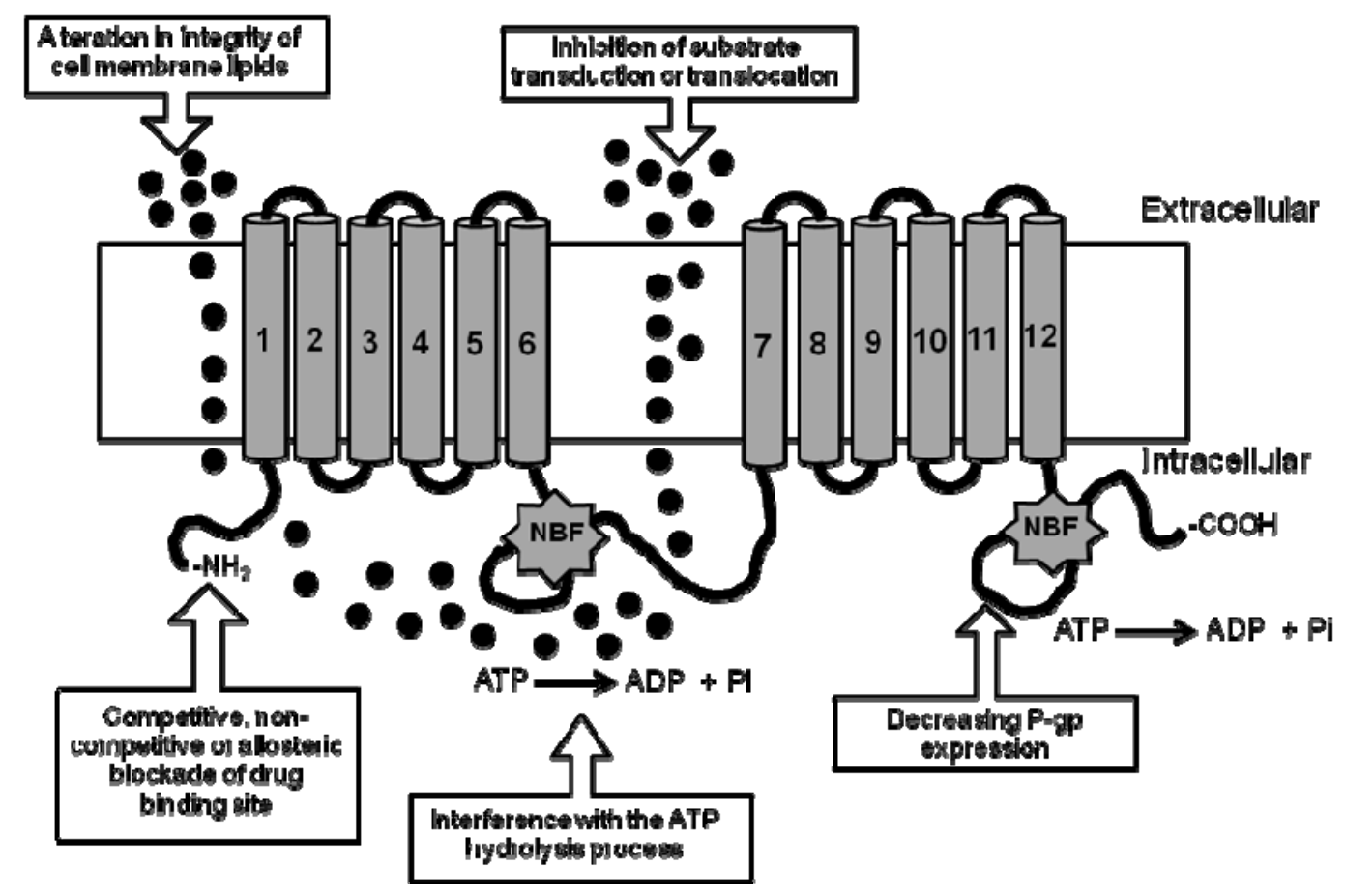

Figure 4. Mechanism of P-gp inhibition

\section{Drug Absorption and oral bioavailability}

Oral administration is particularly essential for anti-cancer drugs, which are to be given chronically, and where time period of exposure is a determinant of anti-cancer activity (145).

Anticancer drugs have low systemic exposure due to their ability to be effluxed by Pgp. The correlation between AUC after oral administration and P-gp content suggests that Pgp in gut wall determines the plasma concentration of P-gp substrates. Significant improvement in oral treatment outcome is noted with etoposide $(146,147)$, topotecan $(143,148$ 150), paclitaxel (151-155) and docetaxel (156), using classical P-gp inhibitors.

Flavonoids have been used as non-toxic P-gp inhibitors for bioavailability enhancement with chemotherapeutic agents. Choi et al. have conducted numerous studies based on P-gp inhibition with flavonoids using paclitaxel and its prodrug with a view to develop safe, moreconvenient, cremophor-free oral formulations. In one of the studies, paclitaxel $(40 \mathrm{mg} / \mathrm{kg})$ and flavone $(2, \quad 10, \quad 20 \mathrm{mg} / \mathrm{kg})$ were orally administered to rats. The plasma concentration of paclitaxel with flavone increased significantly $(P$ $<0.01)$ compared to that of paclitaxel control.
Area under the plasma concentration-time curve (AUC) of paclitaxel with the dose of $2-20 \mathrm{mg} / \mathrm{kg}$ flavone was significantly $(P<0.05$ at $10 \mathrm{mg} / \mathrm{kg}, P$ $<0.01$ at $20 \mathrm{mg} / \mathrm{kg}$ ) higher than that of control. AUCs of paclitaxel were increased dosedependently in the dose range of flavone. The absorption rate constant $\left(\mathrm{K}_{\mathrm{a}}\right)$ of paclitaxel with the dose of $10-20 \mathrm{mg} / \mathrm{kg}$ flavone was significantly increased $(P<0.05$ at $10 \mathrm{mg} / \mathrm{kg}, P<0.01$ at 20 $\mathrm{mg} / \mathrm{kg}$ ) compared to that of control. Peak concentration $\left(\mathrm{C}_{\max }\right)$ of paclitaxel with the dose of $10-20 \mathrm{mg} / \mathrm{kg}$ flavone were significantly increased $(P<0.05$ at $10 \mathrm{mg} / \mathrm{kg}, P<0.01$ at $20 \mathrm{mg} / \mathrm{kg})$ compared to that of control (94). Another study of paclitaxel pretreated with quercetin showed increased plasma concentrations $(P<0: 01$; for paclitaxel; $P<0: 05$; for prodrug) compared to the control. AUC, bioavailability and $\mathrm{C}_{\max }$ of paclitaxel after administration of the paclitaxel or prodrug pretreated with quercetin for 3 days were much higher than those administered after $20 \mathrm{~min}$ (95). Similarly, the purpose of another study was to investigate the bioavailability of paclitaxel after oral administration of paclitaxel and paclitaxel prodrug alone or with naringin. The plasma concentrations of paclitaxel coadministered with 
naringin increased significantly $(P<0.01$ at paclitaxel, $P<0.05$ at prodrug) compared to the control. The bioavailability of paclitaxel coadministered as a prodrug with or without naringin was remarkably higher than the control. Paclitaxel prodrug, a water-soluble compound concerning with its physicochemical properties, passes through the gastrointestinal mucosa more easily than paclitaxel without obstruction of P-gp and CYP 450 in the gastrointestinal mucosa (102).

Tamoxifen is a nonsteroidal antiestrogen and is the agent of choice for treating and preventing breast cancer. Oral tamoxifen undergoes extensive hepatic metabolism and the subsequent biliary excretion of its metabolites. Tamoxifen and its metabolites, and 4hydroxytamoxifen are substrates for the efflux of P-gp, BCRP and MRP 2. The oral bioavailability of tamoxifen is mainly affected by the first-pass metabolism and P-gp pump efflux in the liver and intestine. As a dual inhibitor of the metabolizing enzyme CYP3A and MDR transporter, quercetin might alter the pharmacokinetics of tamoxifen when used concomitantly with tamoxifen. The coadministration of quercetin $(2.5$ and $7.5 \mathrm{mg} / \mathrm{kg})$ significantly $(P<0.05)$ increased the absorption rate constant $\left(K_{\mathrm{a}}\right)$, peak concentration $\left(C_{\max }\right)$ and the areas under the plasma concentration-time curve (AUC) of tamoxifen. The absolute bioavailability $(\mathrm{AB} \%)$ of tamoxifen with 2.5 and $7.5 \mathrm{mg} / \mathrm{kg}$ quercetin ranged from $18.0 \%$ to $24.1 \%$, which was significantly higher than the control group, $15.0 \%(P<0.05)(101)$.

Yet another in-vitro screening study was conducted on flavonoids wherein several food extracts which may have an inhibitory effect on P-gp related efflux carriers including strawberry extract, orange extract, peppermint oil and apricot extract were tested. The results indicated that the co-administration of food extracts with drugs known to be P-gp substrates might be a useful, safe and convenient way to enhance the intestinal absorption of these drugs (49).

\section{Tissue Distribution: Blood brain barrier}

The treatment of primary or metastatic brain tumors with chemotherapy is limited because of a low distribution of anticancer agents into brain tissue. An important reason for this low efficacy is the efficient protection of the brain against drugs involving two drug permeability barriers: (i) the blood-brain barrier (BBB); and (ii) the blood-cerebrospinal fluid (CSF) barrier. The blood-brain barrier is formed primarily by the endothelium of the blood capillaries. Diffusion of some hydrophobic drugs through the endothelial cell membrane is counteracted by transporters such as P-gp that are present in the apical (luminal) membranes of these cells, as was shown initially in mice (153). The blood-CSF barrier is formed by the epithelium of the choroid plexus, which also contains transport proteins, such as $\mathrm{ABCC} 1$, that act as a barrier for certain drugs entering from the blood. This implies that specific inhibitors of P-gp and other drug transporters present in these barriers can be useful to increase the permeability of the blood-brain barrier and the blood-CSF barrier for anticancer drugs, which might enable the treatment with chemotherapy of primary brain tumors with an intact blood-brain barrier $(157,158)$. Preclinical studies have shown that the central nervous system (CNS) penetration of anticancer drugs, which are transported by Pgp, such as paclitaxel (159), etoposide $(160,161)$, doxorubicin, (162) and imatinib (163-166), can indeed be improved by concomitant use of P-gp inhibitors, such as cyclosporin A, valspodar, elacridar and zosuquidar (13).

Understanding mechanisms associated with beneficial effects produced by flavonoids are complicated by the lack of information on the ability of flavonoids to enter the CNS. One of the studies conducted by Youdim et al. examined naringenin and quercetin permeability across the blood-brain barrier, using in vitro (ECV304/C6 co-culture) and in situ (rat) models. The results demonstrate that flavonoids are able to traverse the BBB in vivo. However, the permeability of certain flavonoids in vivo is influenced by their lipophilicity and interactions with efflux transporters (103). Mitsunaga et al. investigated the effects of various bioflavonoids on the bloodbrain barrier transport of vincristine using both in vitro transport experiments with cultured mouse brain capillary endothelial cells (MBEC4 cells) and in vivo brain distribution experiments in ddY mice. The steady-state uptake of $\mathrm{H}^{3}$ vincristine by MBEC4 cells was decreased by $10 \mu \mathrm{M}$ quercetin, but increased by $50 \mu \mathrm{M}$ quercetin. Similarly, the in vivo brain-to-plasma concentration ratio of $\mathrm{H}^{3}$ vincristine in ddY mice was decreased by coadministration of $0.1 \mathrm{mg} / \mathrm{kg}$ quercetin, but increased by $1.0 \mathrm{mg} / \mathrm{kg}$ quercetin. Kaempferol had a similar biphasic effect on the in vitro uptake of $\mathrm{H}^{3}$ vincristine. Other aglycones tested chrysin, flavone, hesperetin, naringenin increased $\mathrm{H}^{3}$ vincristine uptake in the $10-50 \mu \mathrm{M}$ range, and glycosides hesperidin, naringin, rutin were 
without effect. Therefore it was concluded low concentrations of quercetin indirectly activate the transport by enhancing the phosphorylation and hence activity of P-gp, whereas high concentrations of quercetin inhibit P-gp (98).

\section{Drug Metabolism}

The joint presence of both P-gp and CYP3A in intestinal cells, their overlapping substrate specificity (which implies that they are induced and inhibited by many of the similar compounds) and poor oral bioavailability of compounds which are their substrates strongly indicate that there is some biochemical alliance between the two proteins $(5,167)$. Drug molecules are exposed to P-gp prior to intracellular distribution and metabolism. A fraction of drug molecules is extruded by intestinal P-gp from inside of the epithelial cells into the intestinal lumen after the drug molecules gain access across the luminal surface of the epithelial cells; however, a portion of the extruded drugs then can be reabsorbed into the epithelial cells. Through the repetitive processes of extrusion and reabsorption, P-gp prolongs the intracellular residence time of drug molecules and increases the exposure of drug molecules to drug-metabolizing enzymes. Consequently, P-gp may enhance intestinal metabolism of drugs, while it has less of an effect on drug metabolism in liver and kidney (10).

Presystemic elimination of paclitaxel is also governed by CYP $3 \mathrm{~A} 4$ and $2 \mathrm{C} 8$ isoenzymes present in intestinal wall and liver. Therefore, in addition to P-gp, they may play a role in the low oral bioavailability of paclitaxel (168). It was reported that the plasma AUC of orally administered paclitaxel is more than 6-fold increased in mdr1a (-/-) mice compared to wildtype mice $(155,169)$. Quercetin has been investigated as a dual inhibitor of the metabolizing enzyme CYP3A and MDR transporter and might alter the pharmacokinetics of drugs co-administered (101). Very few studies have been reported in this area and deeper insights would be obtained by further exploration.

\section{Drug Excretion}

The presence of P-gp in bile canaliculi and kidney suggest that P-gp plays an important role in biliary and renal excretion. Therefore pharmacokinetic interactions occur due to impaired biliary and renal excretion mediated by first and second generation P-gp inhibitors that are coadministered with chemotherapeutic agents. This includes reports of colchicine blockade by Cyclosporin A (CsA), reduced vinblastine elimination caused by CsA, doxorubicin biliary clearance inhibition by PSC 833 and GF120918 as well as irinotecan clearance by loperamide and PSC-833 (1, 170, 171). Particular examples include paclitaxel(172-176), doxorubicin (177, 178), vinblastine (179) and irinotecan $(180,181)$ where increases in anticancer drug plasma exposure (i.e. increased elimination half-lives and AUC) has occurred. Liver P-gp mediates the efflux of chemicals from hepatocytes into the biliary canaliculus, a phase III elimination reaction. In freshly-plated hepatocytes, containing a low amount of P-gp, flavonols did not affect the cellular retention of doxorubicin, but strongly inhibited the P-gp mediated efflux of rhodamine123 (99).

\section{Elucidation of drug interactions}

Serious drug-drug interactions have contributed to recent U.S. market withdrawals and also recent non approvals of a few new molecular entities. Many of these interactions involved the inhibition or induction of metabolizing enzymes and efflux transporters, resulting in altered systemic exposure and adverse drug reactions or loss of efficacy. In addition to drug-drug interactions, drug-dietary supplement and drug-citrus fruit interactions, among others, could also cause adverse drug reactions or loss of efficacy and are important issues to consider in the evaluation of new drug candidates. Several studies indicate that patients taking drugs which are P-gp substrates may need to restrict their intake of bioflavonoidcontaining foods and beverages, such as grapefruit juice (182).

The importance of food effects and fooddrug interactions at the level of the intestinal mucosa has been identified and several interactions between food and P-gp have also been described (183). The inhibition and reversal of P-gp by rosemary extract has been reported (87). Orange juice, grapefruit juice and extracts, and several compounds of these citrus fruits have been investigated for their inhibitory effect on Pgp-related efflux mechanisms $(74,75,86,105$, 184). In an in-vitro screening study, it was showed that several food extracts may have an inhibitory effect on P-gp-related efflux carriers including strawberry extract, orange extract, peppermint oil and apricot extract (49). 


\section{Reversal of Multi-Drug Resistance}

One of the major problems related with anticancer chemotherapy is resistance against anticancer drugs. Some cancers such as non-small cancer, lung cancer, and rectal cancer show what is called primary resistance or natural resistance in which they do not respond to standard chemotherapy drugs from the beginning. On the other hand, many types of sensitive tumors respond well to chemotherapy drugs in the beginning but show acquired resistance later (185). Treatment induced acquired resistance complicates efforts to successfully cause long-term regression or cure. As described previously, a number of mechanisms have been shown to exist under the generalized MDR (186). Among these mechanisms, the role of P-gp in MDR is best characterized. P-gp occurrence in clinical tumors has been extensively characterized and P-gp overexpression has been shown to occur both during diagnosis as well as during relapse. For example, P-gp was detected at the time of diagnosis in leukemias; lymphomas; adult and childhood sarcomas (187), and neuroblastomas (1). P-gp has low substrate specificity and can bind with various kinds of compounds to transport drugs out of the cells. It follows that once P-gp expresses in cancer cells, the cells will acquire resistance to many other anti-cancer agents. In fact, it is known that many structurally different anti-cancer agents such as adriamycin, vinblastine, vincristine, actinomycin $\mathrm{D}$, colchicine become a substrate for transporting outside cells by P-gp. Therefore, it is considered that inhibiting the function of P-gp will lead to overcoming multidrug resistance. It is reported that about $30 \%$ of multidrug resistances is caused by P-gp. The addition of verapamil, diltiazem, quinine, trifluoperazine or cyclosporin seems to potentially reverse P-gp associated MDR (142).

Taking into consideration that flavonoid derivatives possess antitumor promoter activity, they may become candidates of effective multidrug resistance-reversing agents in cancer chemotherapy. Pentamethylquercetin, pentaallylquercetin and pentaethylmorin remarkably increased the uptake of $[3 \mathrm{H}]$ vincristine by K562/ADM cells by $10.6,10.8$ and 14.4-fold, respectively. These inhibitory potencies for P-gp were more potent than typical P-gp inhibitors, cyclosporine A and verapamil (97). Flavonoid derivatives such as nobiletin, tangeretin and 3,30,40,5,6,7,8heptamethoxyflavone increase the cellular uptake of vincristine in multidrug-resistant tumor cells by inhibiting the function of P-gp (74). The naturally occurring flavonoids biochanin A, morin, phloretin, and silymarin can inhibit P-gpmediated drug efflux, and biochanin $\mathrm{A}$ and silymarin can potentiate doxorubicin cytotoxicity in P-gp positive cells (80). Methoxyflavones also increased the uptake of $\left[{ }^{3} \mathrm{H}\right]$ vincristine into an adriamycin-resistant variant of human chronic myelogenous leukemia (K562/ADM) cells (100). Exposure to $200 \mu \mathrm{M}$ genistein elicited an elevation in intracellular accumulation of rhodamine 123 and daunorubicin in P-gp expressing cell lines. There was also a decrease in photoaffinity labeling of $\mathrm{P}$-gp by $\left[{ }^{3} \mathrm{H}\right]$ azidopine, a P-gp substrate. Therefore it may be concluded that genistein interacts with P-gp and inhibits Pgp mediated drug transport (107). Among tea catechins, especially epigallocatechin gallate, seem to be a promising natural dietary compound for overcoming the multidrug resistance that derives from the active efflux of anti-tumour drugs by P-gp (104).

\section{EXPERIMENTAL MODELS FOR P-GP MEDIATED STUDIES}

Various in vitro and in vivo models are available for studying P-gp mediated efflux. The choice of model depends on the objectives of the study, which could be identification of substrates during early drug discovery or more mechanistic determinations (188). Although it is well recognized that not every inhibitor is a substrate, it is generally believed that every substrate should be an inhibitor. However, this may not be the case for P-gp as many P-gp substrates have relatively low affinity for the protein and do not significantly inhibit P-gp at reasonable working concentrations. Doxorubicin and etoposide which are generally recognized as good P-gp substrates show little inhibition of P-gp efflux of calcein AM, even at high concentrations (189). The failure of P-gp substrates to show significant inhibitory potential is further illustrated in a study in which 167 diverse compounds were classified according to whether they were P-gp substrates and/or P-gp inhibitors (190). These results illustrate the limitations of using one type of assay system to extrapolate another type of activity (ie. binding data and inhibition studies are not sufficient to identify potential P-gp substrates). Instead, direct measures of P-gp transport are required to identify whether or not a compound is a P-gp substrate, and inhibition studies are required to assess if a compound is a potential 
inhibitor. The various models are described under following heading.

\section{In-silico prediction}

The ability to predict the potential of a compound to interact with P-gp based on its structural features would be one of the most efficient means for early screening of compounds. However, P-gp substrates and inhibitor show considerable diversity and the structural requirements for interaction with P-gp are not well resolved. Earlier models suggest that P-gp substrates are large amphipathic molecules with a basic amine and two or more aromatic rings (191). However, exceptions to each of these structural criteria have been identified. P-gp substrates have been identified that are low molecular weight molecules (such as cimetidine 250 daltons), cations, anions, zwitterions, and neutral compounds, peptides and non-peptides. Thus, simple structural predictions to identify compounds that interact with P-gp are not very effective. Recently A. Seelig (192) used molecular modeling approaches to compare the structures of $100 \mathrm{P}$-gp substrates, inhibitors and inducers, as well as compounds which do not interact with P-gp. All of the compounds that interacted with P-gp had 2 or more hydrogen bond acceptors (electron donors) separated by 4.6 $\AA$ or 3 acceptors positioned $2.5 \AA$ from each other. While this model needs further validation, some recent studies within homologous structural series suggest a correlation between hydrogen bond acceptor potential and the ability of compounds to interact with P-gp (193). Pharmacophore models for in silico prediction of P-gp substrate and modulators have been generated. The descriptors such as lipophilicity, hydrogen-bonding ability, presence of an amine, molecular weight, size, surface area and presence of rings are found to correlate well with databases (194). Unfortunately, conclusive SAR for substrate and inhibitory activity has not been found and has led to misclassification of compounds. Therefore, more specific approaches need to be developed which would help in elucidating separate SAR.

\section{In-vitro models}

These include cytotoxicity assay, accumulation/efflux assays, transport assays, ATPase assay and P-gp photoaffinity labeling. They help in classification of compounds as substrates (transported and non-transported), inhibitors and inducers. These models are generally used in early drug discovery for lead selection and optimization (195).

\section{Cytotoxicity Assays}

The use of cytotoxicity $\mathrm{IC}_{50}$ endpoints (the concentration that inhibits the growth of the MDR expressing cells by $50 \%$ ) is a frequently used method to evaluate P-gp substrates and inhibitors. Most often the $\mathrm{IC}_{50}$ for several concentration of a cytotoxic drug is evaluated in the presence and absence of a non-toxic concentration of a P-gp modulator. Modulators interact with P-gp and reduce the efflux of the cytotoxic compound, resulting in the increase in apparent toxicity of the cytotoxic compound. The data from this assay is based on a general assessment of cytotoxicity although more than one mechanism may act in the resistant cells. Furthermore, the values obtained vary greatly depending on the cell type used, the intrinsic cytotoxicity of the compounds and the concentration of P-gp interacting agents used in the studies (194).

\section{Accumulation/Efflux Assay}

Another popular method is the measurement of drug uptake or drug accumulation; performed on cell suspension, cell monolayer or membrane vesicle preparation. In this assay, the accumulation of a probe (a radiolabeled or fluorescent P-gp substrate) over time is measured in the presence or absence of a known P-gp inhibitor. Drug accumulation in the P-gp expressing cells is then compared with accumulation in cells from the low P-gpexpression parental cell line. Since P-gp transports substrates out of the cell, P-gp substrates show lower accumulation in P-gp expressing cells than in the P-gp deficient cells. Similarly, drug accumulation is increased under conditions where P-gp is inhibited, such that the difference in accumulation in parental cells and Pgp over-expressing cells becomes insignificant (196).

A modification of accumulation assay involves the use of photoaffinity analogs of antitumor agents that are P-gp substrates $(197,198)$. Such measurements are used to determine the 'true' binding affinity of the substrates to P-gp. Furthermore, they are direct and reproducible functional assay for P-gp dependent transport with few drawbacks. The commonly used 
fluorescent dyes like rhodamine 123 and 3', 3', 9diethyloxocarbocyanine iodide do not represent the exact anti-tumor drug and often the fluorescence of the probe is quenched inside the cell making quantitation difficult (199). Thorough evaluation of the data is therefore needed when efflux P-gp inhibition studies are used for Quantitative SAR (QSAR) modelling $(188,194)$.

\section{Transport Assays}

Transport studies using adherent cells have been used to screen P-gp substrates and inhibitors. They provide the most direct model for emulating the passage of molecules across the biological barriers encountered in drug pathway. In the transport assays, polarized epithelial cells are used that constitutively express high levels of P-gp (i.e. Caco-2 cells) or have been transfected with the gene for a specific P-gp (i.e. MDR1 transfected MDCK or LLC PK1 cells). Intact monolayers of these cells grown on semi-permeable filters represent a partial barrier to drug transport between the apical and basolateral compartments. In these types of studies, permeability studies in the apical-to-basolateral (A-B) and in the basolateral-to-apical (B-A) direction are performed. The ratio of these numbers is compared with a value of one and indicates P-gp involvement (200). This is regarded as the standard for identifying P-gp substrates since it measures efflux in the most direct manner. However, monolayer efflux assays are laborintensive due to cell culture and analytical requirements limit the assay throughput (7). In addition, interpretation of data from this type of study is complicated by the fact that these cell lines are often very heterogeneous and possess several different transport pathways that can be going on in parallel. This can make it very difficult to understand the data and weed out the effect of efflux on the transport by P-gp (194).

\section{ATPase Assays}

ATPase enzyme activity is necessary P-gp mediated transport and both NBD's of P-gp must hydrolyze nucleotides for transport to take place. The stimulation / inhibition of P-gp ATPase activity in membranes obtained from cells that express P-gp can be monitored. Assays are based on the assumption that drug-induced ATP hydrolysis reflects transport by the transporter. It has been proposed that substrates can be characterized based on their kinetic parameters derived from the assay $(201,202)$. However, the validity of this assay for differentiation between substrates and inhibitors has recently been questioned. Furthermore, compounds such as daunomycin and vinblastine have been observed to inhibit ATPase activity in some investigations, but increase in others, suggesting that modulation of ATPase activity is highly dependent on experimental conditions and may not correlate well with the ability of P-gp to transport the drug (194).

\section{In vivo models}

In vivo models determine the ultimate impact of drug efflux transporters on ADME. Both transgenic/Knock-out (where the animals are genetically manipulated to demonstrate the role of a particular protein), or mutant models (where the animal is deficient in expressing a protein naturally) have been used successfully for assessing drug efflux transporter activity. The pharmacokinetic properties such as the enhancement of brain penetration, improved oral systemic exposure, or reduced biliary excretion of test compounds were observed in single knock out (mdrla(-/-)) or double knock out (mdrla/lb (-/-)) animals (188). Similar pharmacokinetic differences in normal animals in the presence of a P-gp inhibitor/inducer have also been used to predict P-gp involvement. CF-1 mice (P-gp mutant strain) have been used to screen compounds for P-gp interactions. Although there is high conservation and homology in mdr1/MDR1 genes among species (203), the removal of genes affect tissues other than the organ of interest, which may lead to undesirable outcomes such as altered pharmacokinetics and systemic toxicity.

Despite the widespread use of rodent / human microsomes, liver slices and cDNA-based vector systems, optimal preclinical in vitro or in vivo model that enable accurate extrapolation of the preclinical data about oral pharmacokinetics to the clinic are lacking. Interspecies variation in CYP isoform activity, involvement of active transport by P-gp or other unidentified transporters and presence of extrahepatic and gut wall metabolism may lead to inaccuracies. There is a strong need for development of such tools and mechanistic insights which allow adequate prediction of the pathways of biotransformation, first-pass metabolism, drug-drug interactions and oral pharmacokinetics of new anticancer agents during the early preclinical phase of drug 
development. These insights could then be useful to optimize the pharmacokinetics of anti-cancer drugs, by selective inhibition of drug metabolism pathways and/or drug-transport processes (Figure 5) (169).

\section{CONCLUSIONS}

Classical P-gp suppressing agents appeared to exert unwanted side effects, and this stimulated the interest in flavonoids as relatively noncytotoxic inhibitors of P-gp. It has become clear that flavonoids are important modulators of intestinal transport proteins particularly P-gp. Many flavonoids have been shown to interact with P-gp mediated efflux in vitro studies, and the potential consequences for the same are being studied in vivo. However, the significance of these flavonoid-efflux transporter interactions in pharmacokinetic interactions has not been unequivocally demonstrated. Since the involvement of multiple drug transporters and metabolizing enzymes in the disposition of substrates can mystify the interpretation of in vivo studies, more specific substrates are needed to clearly address this issue. P-gp inhibition has originally been studied within the framework of classical reversal of multi-drug resistance. Identification of P-gp modulators among herbal compounds would make them perfect candidates for bioavailability enhancement, tissuepenetration (e.g. blood brain barrier), decreasing biliary excretion and multi-drug resistance modulating agents. Future studies should be focused to explore i) in vivo evaluation of the flavonoid-mediated effects on bioavailability of drugs in animals and humans ii) identification and prediction of potential herb-drug interactions iii) modulating the activity of the flavonoids to act as CYP3A4 inhibitors and/or substrates.

\section{HIGH THROUGHPUT}

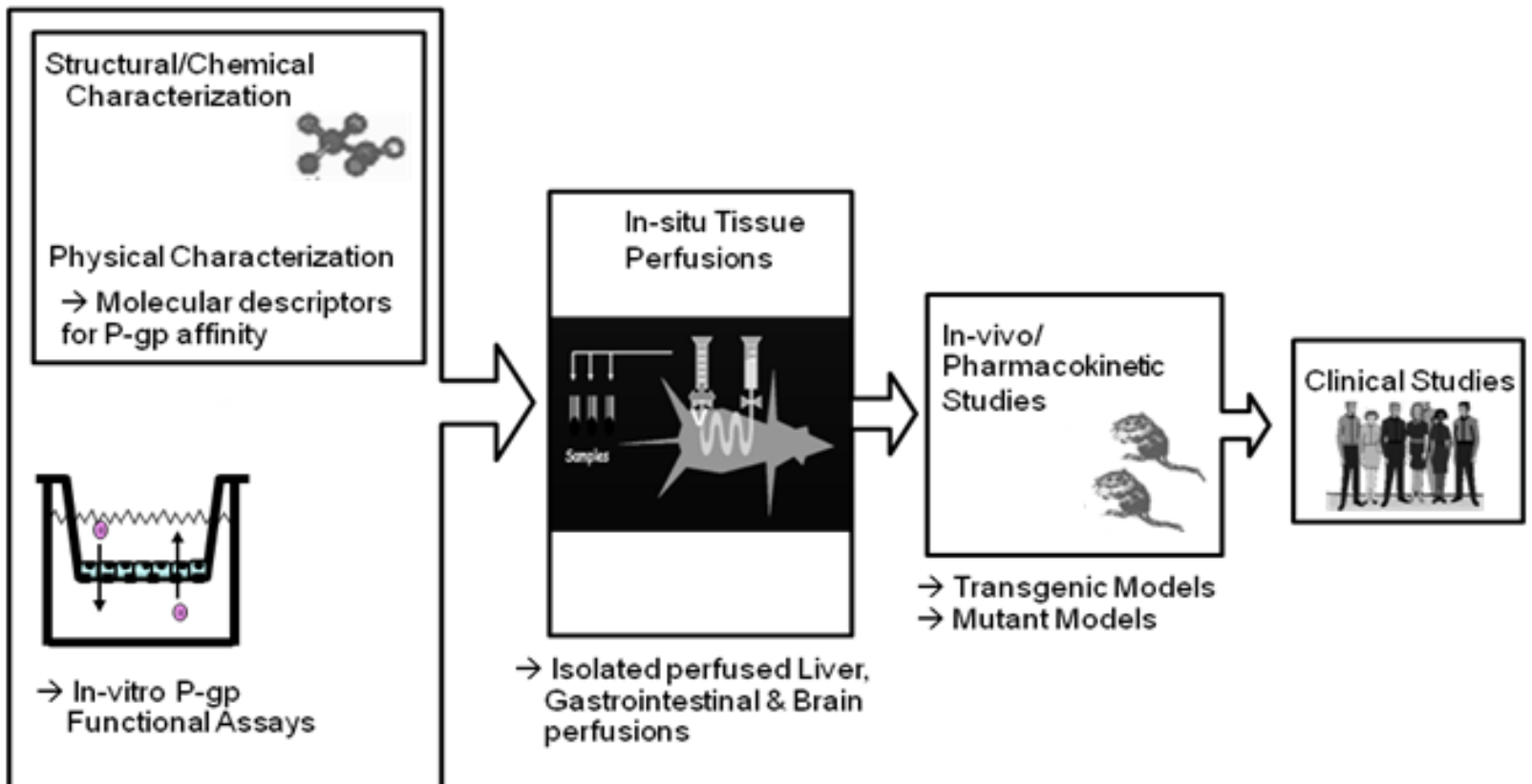

Figure 5. Various approaches to identify drugs that may interact with P-gp. These are in-silico, in-vitro and in-vivo (animal and human studies) models. The hierarchy shows the increased cost and decreased ability of conducting high throughput from in-silico to human studies. More than one model may be used in combination to obtain useful and sufficient information. 


\section{REFERENCES}

[1]. Krishna, R., and Mayer, L. D. Multidrug resistance (MDR) in cancer mechanisms, reversal using modulators of MDR and the role of MDR modulators in influencing the pharmacokinetics of anticancer drugs. Eur. J. Pharm. Sci., 11: 265-283, 2000.

[2]. Juliano, R. L., and Ling, V. A surface glycoprotein modulating drug permeability in Chinese hamster ovary cell mutants. Biochim. Biophys. Acta, 455: 152-162, 1976.

[3]. Schinkel, A. H., and Jonker, J. W. Mammalian drug efflux transporters of the ATP binding cassette (ABC) family: an overview. Adv. Drug Deliv. Rev., 55: 3-29, 2003.

[4]. Ambudkar, S. V., Dey, S., Hrycyna, C. A., Ramchandra, M., Pastan, I., and Gottesman, M. M. Biochemical, cellular, and pharmacological aspects of the multidrug transporter. Annu. Rev. Pharmacol. Toxicol., 39: 361-398, 1999.

[5]. Benet, L. Z., and Cummins, C. L. The drug efflux-metabolism alliance: biochemical aspects. Journees Galeniques, 94: 9-16, 2001.

[6]. Hunter, J., and Hirst, B. H. Intestinal secretion of drugs. The role of P-glycoprotein and related drug efflux systems in limiting oral drug absorption. Adv. Drug Del. Rev., 25: 129-157, 1997

[7]. Polli, J. W., Wring, S. A., Humphreys, J. E., Huang, L., Morgan, J. B., Webster, L. O., and Singh, C. S. S. Rational use of in vitro Pglycoprotein assays in drug discovery. J. Pharmacol. Exp. Ther., 299: 620-628, 2001.

[8]. Tandon, V. R., Kapoor, B., Bano, G., Gupta, S., Gillani, Z., Gupta, S., and Kour, D. Pglycoprotein: Pharmacological relevance. Indian J Pharmacol, 38: 13-24, 2006

[9]. Varma, M. V., Perumal, O. P., and Panchagnula, R. Functional role of Pglycoprotein in limiting peroral drug absorption: optimizing drug delivery. Curr Opin Chem Biol, 10: 367-373, 2006.

[10]. Lin, J. H. Drug-drug interaction mediated by inhibition and induction of P-glycoprotein. Adv. Drug Deliv. Rev., 55: 53-81, 2003.

[11]. Dantzig, A. H., Shepard, R. L., Cao, J., Law, K. L., Ehlhardt, W. J., Baughman, T. M., Bumol, T. F., and Starling, J. J. Reversal of Pglycoprotein-mediated multidrug resistance by a potent cyclopropyldibenzosuberane modulator, LY335979. Cancer Res, 56: 41714179, 1996.

[12]. Hyafil, F., Vergely, C., Du Vignaud, P., and Grand-Perret, T. In vitro and in vivo reversal of multidrug resistance by GF120918, an acridonecarboxamide derivative. Cancer Res, 53: 4595-4602, 1993.
[13]. Breedveld, P., Beijnen, J. H., and Schellens, J. $H$. Use of P-glycoprotein and BCRP inhibitors to improve oral bioavailability and CNS penetration of anticancer drugs. Trends Pharmacol Sci, 27: 17-24, 2006.

[14]. Dantzig, A. H., de Alwis, D. P., and Burgess, M. Considerations in the design and development of transport inhibitors as adjuncts to drug therapy. Adv Drug Deliv Rev, 55: 133-150, 2003.

[15]. Loo, T. W., and Clarke, D. M. Recent progress in understanding the mechanism of P-glycoprotein-mediated drug efflux. J Membr Biol, 206: 173-185, 2005.

[16]. Booth, C. L., Pulaski, L., Gottesman, M. M., and Pastan, I. Analysis of the properties of the $\mathrm{N}$-terminal nucleotide-binding domain of human P-glycoprotein. Biochemistry, 39: 5518-5526, 2000.

[17]. Tombline, G., Bartholomew, L., Gimi, K., Tyndall, G. A., and Senior, A. E. Synergy between conserved $\mathrm{ABC}$ signature Ser residues in P-glycoprotein catalysis. J Biol Chem 279: 5363-5373, 2004.

[18]. Ambudkar, S. V., Kim, I. W., and Sauna, Z. E. The power of the pump: mechanisms of action of P-glycoprotein (ABCB1). Eur $\mathrm{J}$ Pharm Sci, 27: 392-400, 2006.

[19]. Yasuhisa, K., Michinori, M., Kei, T., Tohru, S., and Noriyuki, K. ATP hydrolysis dependent multidrug efflux transporter: MDR1/P-glycoprotein. Current Drug Metabolism, 5: 1-10, 2004.

[20]. Thiebaut, F., Tsumo, T., Hamada, H., Gottesman, M. M., Pastan, I., and Willingham, M. C. Cellular localisation of the multidrug resistance gene product $\mathrm{P}$ glycoprotein in normal human tissues. Proc. Natl. Acad. Sci. USA, 84: 7735-7738, 1987.

[21]. Croop, J. M., Raymond, M., Haber, D., A., D., Arceci, R. J., Gros, P., and Housman, D. E. The three mouse multidmg resistance (mdr) genes are expressed in a tissue-specific manner in normal mouse tissues. Mol. Cell. Biol., 9: 1346-1350, 1989.

[22]. Arceci, R. J., Croop, J. M., Horwitz, S., and Housman, D. The gene encoding multidrug resistance is induced and expressed at high levels during pregnancy in the secretory epithelium of the uterus. Proc. Natl. Acad. Sci. USA, 85: 4350-4354, 1988.

[23]. Joly, B., Fardel, O., Cecchelli, R., Chesn, C., Puozzo, C., and Guillouzo, A. Selective drug transport and P-glycoprotein activity in an in vitro blood-brain barrier model. Tox. In Vitro, 9: 357-364, 1995. 
[24]. Fardel, O., Lecureur, V., and Guillouzo, A. The P-Glycoprotein Multidrug Transporter. Gen. Pharmac., 27: 1283-1291, 1996.

[25]. Ito, K., Suzuki, H., Horie, T., and Sugiyama, Y. Apical/Basolateral Surface Expression of Drug Transporters and its Role in Vectorial Drug Transport. Pharm Res, 22: 1559-1577, 2005.

[26]. Drach, D., Zhao, S., Drach, J., and Anoheeff, M. Low incidence of MDR1 expression in acute promyelocytic leukaemia. Br. J. Haematol., 90: 369-374, 1995.

[27]. Abolhoda, A., Wilson, A. E., Ross, H., Danenberg, P. V., Burt, M., and Scotto, K. W. Rapid activation of MDR1 gene expression in human metastatic sarcoma after in vivo exposure to doxorubicin. Clin. Cancer Res. , 5: 3352-3356, 1999.

[28]. Thomas, H., and Coley, H. M. Overcoming multidrug resistance in cancer: an update on the clinical strategy of inhibiting $\mathrm{P}$ glycoprotein. Cancer Control, 10: 159-165, 2003.

[29]. Ino, T., Miyazaki, H., Isogar, M., Nomura, T., Tsuzuki, M., Tsuruo, T., Ezaki, K., and Hirano, M. Expression of $\mathrm{P}$ glycoprotein in de now) acute myclogenous leukemia at initial diagnosis: results of molecular and functional assays and correlation with treatment outcome. Leukemia, 8: 1492-1497, 1994

[30]. Ozben, T. Mechanisms and strategies to overcome multiple drug resistance in cancer. FEBS Letters 580: 2903-2909, 2006.

[31]. Ueda, K., Taguchi, Y., and Morishima, M. How does P-glycoprotein recognize its substrates. Semin Cancer Biol 8: 151-159, 1997.

[32]. Sauna, Z. E., and Ambudkar, S. V. Evidence for a requirement for ATP hydrolysis at two distinct steps during a single turnover of the catalytic cycle of human P-glycoprotein. Proc Natl Acad Sci, 97: 2515-2520, 2000.

[33]. Varma, M., Ashokraj, Y., Dey, C. S., and Panchagnula, R. P-glycoprotein inhibitors and their screening: a perspective from bioavailability enhancement. Pharmacol. Res., 48: 347-359, 2003.

[34]. Sharom, F. J. The P-glycoprotein efflux pumps: how does it transport drugs? J. Memb. Bio., 160: 161-175, 1997.

[35]. Rosenberg, M. F., Kamis, A. B., Collaghan, R., Higgins, C. F., and Ford, R. C. Threedimensional structures of the mammalian multidrug resistance P-glycoprotein demonstrate major conformational changes in the transmembrane domains upon nucleotide binding. J Biol Chem, 278: 8294-8299, 2003.

[36]. Sauna, Z. E., Smith, M. M., Muller, M., Kerr, K. M., and Ambudkar, S. V. The mechanism of action of multidrug-resistance-linked P- glycoprotein. J. Bioener. Biomemb., 33: 481491, 2001.

[37]. Loo, T. W., and Clarke, D. M. Do drug substrates enter the common drug-binding pocket of P-glycoprotein through "gates"? Biochem Biophys Res Commun, 329: 419422, 2005.

[38]. Tsuruo, T., Iida, H., Tsukagoshi, S., and Sakurai, Y. Overcoming of vincristine resistance in P388 leukemia in vivo and in vitro through enhanced cytotoxicity of vincristine and vinblastine by verapamil. Cancer Res., 41: 1967-1972, 1981.

[39]. Schoenhard, G. L., Inhibitors of ABC drug transporters at the blood-brain barrier Pain Therapeutics, Inc., US patent No. 7,034,036 (2006).

[40]. Liscovitch, M., and Lavie, Y. Cancer multidrug resistance: A review of recent drug discovery research. IDrugs, 5: 1-7, 2002.

[41]. Dintaman, J. M., and Silverman, J. A. Inhibition of P-glycoprotein by D-alphatocopheryl polyethylene glycol 1000 succinate (TPGS). Pharm. Res., 16: 15501556, 1999.

[42]. Huang, J., Si, L., Jiang, L., Fan, Z., Qiu, J., and Li, G. Effect of pluronic F68 block copolymer on P-glycoprotein transport and CYP3A4 metabolism. Int J Pharm, 356: 351353,2008

[43]. Kabanova, A. V., Batrakova, E. V., and Alakhov, V. Y. Pluronic block copolymers for overcoming drug resistance in cancer. Adv Drug Deliv Rev, 54: 759-779, 2002.

[44]. Zhou, S., Lim, L. Y., and Chowbay, B. Herbal modulation of P-glycoprotein. Drug Metab Rev, 36: 57-104, 2004.

[45]. Rege, B. D., Kao, J. P. Y., and Polli, J. E. Effects of nonionic surfactants on membrane transporters in Caco-2 cell monolayers. Eur J Pharm Sci, 16: 237-246, 2002.

[46]. Regev, R., Katzir, H., Yeheskely-Hayon, D., and Eytan, G. D. Modulation of Pglycoprotein-mediated multidrug resistance by acceleration of passive drug permeation across the plasma membrane. FEBS J., 274: 6204-6214, 2007.

[47]. Buggins, T. R., Dickinson, P. A., and Taylor, G. The effects of pharmaceutical excipients on drug disposition. Adv Drug Deliv Rev, 59: 1482-1503, 2007.

[48]. Deferme, S., and Augustijns, P. The effects of food components on the absorption of P-gp substrates: a review. J. Pharm. Pharmacol., 55: 153-162, 2003.

[49]. Deferme, S., Gelder, J. V., and Augustijns, P. Inhibitory effect of fruit extracts on Pglycoprotein related efflux carriers: an in vitro screening. J. Pharm. Pharmacol., 54: 12131219, 2002. 
[50]. Brand, W., Schutte, M. E., Williamson, G., van Zanden, J. J., Cnubben, N. H., Groten, J. P., van Bladeren, P. J., and Rietjens, I. M. Flavonoid-mediated inhibition of intestinal $\mathrm{ABC}$ transporters may affect the oral bioavailability of drugs, food-borne toxic compounds and bioactive ingredients. Biomed Pharmacother, 60: 508-519, 2006.

[51]. Chavez, M. L., Jordan, M. A., and Chavez, P. I. Evidence-based drug--herbal interactions. Life Sci, 78: 2146-2157, 2006.

[52]. Cornaire, G., Woodley, J., Hermann, P., Cloarec, A., Arellano, C., and Houin, G. Impact of excipients on the absorption of $\mathrm{P}$ glycoprotein substrates in vitro and in vivo. Int J Pharm, 278: 119-131, 2004.

[53]. Marchetti, S., Mazzanti, R., Beijnen, J. H., and Schellens, J. H. Concise review: Clinical relevance of drug drug and herb drug interactions mediated by the $\mathrm{ABC}$ transporter ABCB1 (MDR1, P-glycoprotein). Oncologist, 12: 927-941, 2007.

[54]. Morris, M. E., and Zhang, S. Flavonoid-drug interactions: effects of flavonoids on $\mathrm{ABC}$ transporters. Life Sci, 78: 2116-2130, 2006.

[55]. Pal, D., and Mitra, A. K. MDR- and CYP3A4-mediated drug-herbal interactions. Life Sci, 78: 2131-2145, 2006.

[56]. Yang, C. Y., Chao, P. D., Hou, Y. C., Tsai, S. Y., Wen, K. C., and Hsiu, S. L. Marked decrease of cyclosporin bioavailability caused by coadministration of ginkgo and onion in rats. Food Chem Toxicol, 44: 1572-1578, 2006.

[57]. Yoshida, N., Takagi, A., Kitazawa, H., Kawakami, J., and Adachi, I. Inhibition of Pglycoprotein-mediated transport by extracts of and monoterpenoids contained in Zanthoxyli fructus. Toxicol Appl Pharmacol, 209: 167173, 2005.

[58]. Zhou, S. F., Zhou, Z. W., Li, C. G., Chen, X., $\mathrm{Yu}, \mathrm{X}$., Xue, C. C., and Herington, A. Identification of drugs that interact with herbs in drug development. Drug Discov Today, 12: 664-673, 2007.

[59]. Bailey, D., Spence, J., Munoz, C., and Arnold, J. Interaction of citrus juices with felodipine and nifedipine. Lancet, 337: 268269, 1991.

[60]. Zhou, S. F., and Lai, X. An update on clinical drug interactions with the herbal antidepressant St. John's wort. Curr Drug Metab, 9: 394-409, 2008.

[61]. Peng, S. X., Ritchie, D. M., Cousineau, M., Danser, E., Dewire, R., and Floden, J. Altered oral bioavailability and pharmacokinetics of P-glycoprotein substrates by coadministration of biochanin A. J Pharm Sci, 95: 1984-1993, 2006.
[62]. Evans, A. M. Influence of dietary components on the gastrointestinal metabolism and transport of drugs. . Ther. Drug Monit., 22: 131-136, 2000

[63]. Walter-Sack, I., and Klotz, U. Influence of diet and nutritional status on drug metabolism. Clin. Pharmacokinet., 31: 47-64, 1996.

[64]. Wilkinson, G. R. The effects of diet, aging and disease-states on presystemic elimination and oral drug bioavailability in humans. Adv. Drug Deliv. Rev. , 27: 129-159, 1997.

[65]. Zhou, S. F., Gao, Y. H., Wen, Q. J., Huang, M., Xu, A. L., and Paxton, J. W. Interactions of herbs with cytochrome P450. Drug Metab. Rev., 35: 35-98, 2003.

[66]. Laitinen, L. A., Tammela, P. S., Galkin, A., Vuorela, H. J., Marvola, M. L., and Vuorela, P. M. Effects of extracts of commonly consumed food supplements and food fractions on the permeability of drugs across Caco-2 cell monolayers. Pharm Res, 21: 1904-1916, 2004.

[67]. Piao, Y., Shin, S. C., and Choi, J. S. Effects of oral kaempferol on the pharmacokinetics of tamoxifen and one of its metabolites, 4hydroxytamoxifen, after oral administration of tamoxifen to rats. Biopharm Drug Dispos, 29: 245-249, 2008.

[68]. Zhang, S., Yang, X., and Morris, M. E. Flavonoids Are Inhibitors of Breast Cancer Resistance Protein (ABCG2)-Mediated Transport. Mol Pharmacol, 65: 1208-1216, 2004.

[69]. Havsteen, B. H. The biochemistry and medical significance of the flavonoids. Pharmacol Ther, 96: 67-202, 2002.

[70]. Romiti, N., Tongiani, R., Cervelli, F., and Chieli, E. Effects of curcumin on Pglycoprotein in primary cultures of rat hepatocytes. Life Sci., 62: 2349-2358, 1998.

[71]. Anuchapreeda, S., Leechanachai, P., Smith, M. M., Ambudkar, S. V., and Limtrakul, P. N. Modulation of P-glycoprotein expression and function by curcumin in multidrug-resistant human KB cells. Biochem Pharmacol, 64: 573-582, 2002.

[72]. Foster, B. C., Foster, M. S., Vandenhoek, S., Krantis, A., Budzinski, J. W., Arnason, J. T., Gallicano, K. D., and Choudri, S. An in vitro evaluation of human cytochrome P450 3A4 and P-glycoprotein inhibition by garlic. J. Pharm. Pharm. Sci., 4: 176-184, 2001.

[73]. Kim, S. W., Kwon, H. Y., Chi, D. W., Shim, J. H., Park, J. D., Lee, Y. H., Pyo, S., and Rhee, D. K. Reversal of P-glycoproteinmediated multidrug resistance by ginsenoside $\operatorname{Rg}(3)$. Biochem. Pharmacol. , 65: 75-82, 2003 . 
[74]. Ikegawa, T., Ushigome, F., Koyabu, N., Morimoto, S., Shoyama, Y., Naito, M., Tsuruo, T., Ohtani, H., and Sawada, Y. Inhibition of P-glycoprotein by orange juice components, polymethoxyflavones in adriamycin-resistant human myelogenous leukemia (K562/ADM) cells. Cancer Lett, 160: 21-28, 2000.

[75]. Spahn-Langguth, H., and Langguth, P. Grapefruit juice enhances intestinal absorption of the P-glycoprotein substrate talinolol. Eur. J. Pharm. Sci. , 12: 361-367, 2001.

[76]. Takanaga, H., Ohnishi, A., Matsuo, H., and Sawada, Y. Inhibition of vinblastine efflux mediated by P-glycoprotein by grapefruit juice components in caco-2 cells. Biol Pharm Bull, 21: 1062-1066, 1998.

[77]. Tian, R., Koyabu, N., Takanaga, H., Matsuo, H., Ohtani, H., and Sawada, Y. Effects of grapefruit juice and orange juice on the intestinal efflux of P-glycoprotein substrates. Pharm Res, 19: 802-809, 2002.

[78]. Sadzuka, Y., Sugiyama, T., and Sonobe, T. Efficacies of tea components on doxorubicin induced antitumor activity and reversal of multidrug resistance. Toxicol. Lett., 114: 155-162, 2000.

[79]. Jodoin, J., Demeule, M., and Beliveau, R. Inhibition of the multidrug resistance $\mathrm{P}$ glycoprotein activity by green tea polyphenols. Biochim Biophys Acta, 1542: 149-159, 2002.

[80]. Zhang, S., and Morris, M. E. Effects of the flavonoids biochanin A, morin, phloretin, and silymarin on P-glycoprotein-mediated transport. J Pharmacol Exp Ther, 304: 12581267, 2003.

[81]. Bhardwaj, R. K., Glaeser, H., Becquemont, L., Klotz, U., Gupta, S. K., and Fromm, M. F. Piperine, a major constituent of black pepper, inhibits human P-glycoprotein and CYP3A4. J Pharmacol Exp Ther, 302: 645-650, 2002.

[82]. Durr, D., Stieger, B., Kullak-Ublick, G. A., Rentsch, K. M., Steinert, H. C., Meier, P. J., and Fattinger, K. St. John's wort induces intestinal P-glycoprotein/MDR1 and intestinal and hepatic CYP3A4. Clin. Pharmacol. Ther. , 68: 598-604, 2000.

[83]. Hennessy, M., Kelleher, D., Spiers, J. P., Barry, M., Kavanagh, P., Back, D., Mulcahym, F., and Feely, J. St. John's wort increases expression of P-glycoprotein: implications for drug interactions. Br. J. Clin. Pharmacol., 53: 75-82, 2002.

[84]. Perloff, M. D., von Moltke, L. L., Stormer, E., Shader, R. I., and Greenblatt, D. J. Saint John's wort: an in vitro analysis of $\mathrm{P}$ glycoprotein induction due to extended exposure. Br. J. Pharmacol., 134: 1601-1608, 2001.

[85]. Mathijssen, R. H., Verweij, J., de Bruijn, P., Loos, W. J., and Sparreboom, A. Effects of St. John's wort on irinotecan metabolism. J. Natl. Cancer Inst., 94: 1247-1249, 2002.

[86]. Hu, Z., Yang, X., Ho, P. C., Chan, E., Chan, S. Y., Xu, C., Li, X., Zhu, Y. Z., Duan, W., Chen, X., Huang, M., Yang, H., and Zhou, S. St. John's Wort modulates the toxicities and pharmacokinetics of CPT-11 (irinotecan) in rats. Pharm Res, 22: 902-914, 2005.

[87]. Plouzek, C. A., Ciolino, H. P., Clarke, R., and Yeh, G. C. Inhibition of P-glycoprotein activity and reversal of multidrug resistance in vitro by rosemary extract. Eur. J. Cancer, 35: 1541-1545, 1999.

[88]. Narayana, K. R., Reddy, M. S., Chaluvadi, M. R., and Krishna, D. R. Bioflavonoids classification, pharmacological, biochemical effects and therapeutic potential. Ind. J Pharmacol., 33: 2-16, 2001.

[89]. Ross, S. A., Ziska, D. S., Zhao, K., and ElSohly, M. A. Variance of common flavonoids by brand of grapefruit juice. Fitoterapia, 71: 154-161, 2000.

[90]. Manach, C., Morand, C., Gil-Izquierdo, A., Bouteloup-Demange, C., and Remesy, C. Bioavailability in humans of the flavanones hesperidin and narirutin after the ingestion of two doses of orange juice. European Journal of Clinical Nutrition, 57: 235-242, 2003.

[91]. Dupuy, J., Larrieu, G., Sutra, J. F., Lespine, A., and Alvinerie, M. Enhancement of moxidectin bioavailability in lamb by a natural flavonoid: quercetin. Vet Parasitol, 112: 337-347, 2003.

[92]. Zhang, H., Wong, C. W., Coville, P. F., and Wanwimolruk, S. Effect of the grapefruit flavonoid naringin on pharmacokinetics of quinine in rats. Drug Metabolism and Drug Interactons, 17: 351-363, 2000.

[93]. Lai, M. Y., Hsiu, S. L., Hou, Y. C., Tsai, S. Y., and Chao, P. D. Significant decrease of cyclosporine bioavailability in rats caused by a decoction of the roots of Scutellaria baicalensis. Planta Medica, 70: 132-137, 2004.

[94]. Choi, J. S., Choi, H. K., and Shin, S. C. Enhanced bioavailability of paclitaxel after oral coadministration with flavone in rats. Int J Pharm, 275: 165-170, 2004.

[95]. Choi, J. S., Jo, B. W., and Kim, Y. C. Enhanced paclitaxel bioavailability after oral administration of paclitaxel or prodrug to rats pretreated with quercetin. Eur $\mathrm{J}$ Pharm Biopharm, 57: 313-318, 2004.

[96]. Wang, Y. H., Chao, P. D., Hsiu, S. L., Wen, K. C., and Hou, Y. C. Lethal quercetin- 
digoxin interaction in pigs. Life Sci, 74: 11911197, 2004.

[97]. Ikegawa, T., Ohtani, H., Koyabu, N., Juichi, M., Iwase, Y., Ito, C., Furukawa, H., Naito, M., Tsuruo, T., and Sawada, Y. Inhibition of P-glycoprotein by flavonoid derivatives in adriamycin-resistant human myelogenous leukemia (K562/ADM) cells. Cancer Lett, 177: 89-93, 2002.

[98]. Mitsunaga, Y., Takanaga, H., Matsuo, H., Naito, M., Tsuruo, T., Ohtani, H., and Sawada, Y. Effect of bioflavonoids on vincristine transport across blood-brain barrier. Eur J Pharmacol, 395: 193-201, 2000.

[99]. Chieli, E., Romiti, N., Cervelli, F., and Tongiani, R. Effects of flavonols on Pglycoprotein activity in cultured rat hepatocytes. Life Sci, 57: 1741-1751, 1995.

[100]. Ohtani, H., Ikegawa, T., Honda, Y., Kohyama, N., Morimoto, S., Shoyama, Y., Juichi, M., Naito, M., Tsuruo, T., and Sawada, Y. Effects of various methoxyflavones on vincristine uptake and multidrug resistance to vincristine in P-gpoverexpressing K562/ADM cells. Pharm Res, 24: 1936-1943, 2007.

[101]. Shin, S. C., Choi, J. S., and Li, X. Enhanced bioavailability of tamoxifen after oral administration of tamoxifen with quercetin in rats. Int J Pharm, 313: 144-149, 2006.

[102]. Choi, J. S., and Shin, S. C. Enhanced paclitaxel bioavailability after oral coadministration of paclitaxel prodrug with naringin to rats. Int J Pharm, 292: 149-156, 2005.

[103]. Youdim, K. A., Qaiser, M. Z., Begley, D. J., Rice-Evans, C. A., and Abbott, N. J. Flavonoid permeability across an in situ model of the blood-brain barrier. Free Radic Biol Med, 36: 592-604, 2004.

[104]. Kitagawa, S., Nabekura, T., and Kamiyama, $\mathrm{S}$. Inhibition of P-glycoprotein function by tea catechins in KB-C2 cells. J Pharm Pharmacol, 56: 1001-1005, 2004.

[105]. Takanaga, H., Ohnishi, A., Yamada, S., Matsuo, H., Morimoto, S., Shoyama, Y., Ohtani, H., and Sawada, Y. Polymethoxylated flavones in orange juice are inhibitors of $\mathrm{P}$ glycoprotein but not cytochrome P450 3A4. J Pharmacol Exp Ther, 293: 230-236, 2000.

[106]. Scambia, G., Ranelletti, F. O., Panici, P. B., De Vincenzo, R., Bonanno, G., Ferrandina, G., Piantelli, M., Bussa, S., Rumi, C., Cianfriglia, M., and et al. Quercetin potentiates the effect of adriamycin in a multidrug-resistant $\mathrm{MCF}-7$ human breastcancer cell line: P-glycoprotein as a possible target. Cancer Chemother Pharmacol, 34: 459-464, 1994.
[107]. Castro, A. F., and Altenberg, G. A. Inhibition of drug transport by genistein in multidrugresistant cells expressing P-glycoprotein. Biochem Pharmacol, 53: 89-93, 1997.

[108]. Edwards, D. J., Fitzsimmons, M. E., Schuetz, E. G., Yasuda, K., Ducharme, M. P., Warbasse, L. H., Woster, P. M., Schuetz, J. D., and Watkins, P. 6', 7'Dihydroxybergamottin in grapefruit juice and Seville orange juice: effects on cyclosporine disposition, enterocyte CYP3A4, and Pglycoprotein. Clin Pharmacol Ther, 65: 237244, 1999.

[109]. Jeong, J. M., and Choi, C. H. Enhancement of paclitaxel transport and cytotoxicity by 7,3',4'trimethoxyflavone, a P-glycoprotein inhibitor. J Pharm Pharm Sci, 10: 547-553, 2007.

[110]. Yoshikawa, M., Ikegami, Y., Sano, K., Yoshida, H., Mitomo, H., Sawada, S., and Ishikawa, T. Transport of SN-38 by the wild type of human ABC transporter ABCG2 and its inhibition by quercetin, a natural flavonoid. J Exp Ther Oncol, 4: 25-35, 2004.

[111]. Li, X., and Choi, J. S. Effect of genistein on the pharmacokinetics of paclitaxel administered orally or intravenously in rats. Int J Pharm, 337: 188-193, 2007.

[112]. Bansal, T., Awasthi, A., Jaggi, M., Khar, R. K., and Talegaonkar, S. Pre-clinical evidence for altered absorption and biliary excretion of irinotecan (CPT-11) in combination with quercetin: possible contribution of $\mathrm{P}$ glycoprotein. Life Sci, 83: 250-259, 2008.

[113]. Lin, L. C., Wang, M. N., and Tsai, T. H. Food-drug interaction of (-)-epigallocatechin3-gallate on the pharmacokinetics of irinotecan and the metabolite SN-38. Chem Biol Interact, 174: 177-182, 2008.

[114]. Limtrakul, P., Khantamat, O., and Pintha, K. Inhibition of P-glycoprotein function and expression by kaempferol and quercetin. J Chemother, 17: 86-95, 2005.

[115]. Regev, R., Assaraf, Y. G., and Eytan, G. D. Membrane fluidization by ether, other anesthetics, and certain agents abolishes Pglycoprotein ATPase activity and modulates efflux from multidrug-resistant cells. Eur J Biochem, 259: 18-24, 1999.

[116]. Sachs-Barrable, K., Thamboo, A., Lee, S. D., and Wasan, K. M. Lipid excipients Peceol and Gelucire 44/14 decrease P-glycoprotein mediated efflux of rhodamine 123 partially due to modifying P-glycoprotein protein expression within Caco-2 cells. J Pharm Pharm Sci, 10: 319-331, 2007.

[117]. Maki, N., Hafkemeyer, P., and Dey, S. Allosteric modulation of human Pglycoprotein. Inhibition of transport by preventing substrate translocation and 
dissociation. J Biol Chem, 278: 18132-18139, 2003.

[118]. Watkins, R. E., Maglich, J. M., Moore, L. B., Wisely, G. B., Noble, S. M., Davis-Searles, P. R., Lambert, M. H., Kliewer, S. A., and Redinbo, M. R. A crystal structure of human PXR in complex with the St. John's wort compound hyperforin. Biochemistry, 42: 1430-1438, 2003.

[119]. Drori, S., Eytan, G. D., and Assaraf, Y. G. Potentiation of anticancer-drug cytotoxicity by multidrug-resistance chemosensitizers involves alterations in membrane fluidity leading to increased membrane permeability. Eur J Biochem, 228: 1020-1029, 1995.

[120]. Arora, A., Byrem, T. M., Nair, M. G., and Strasburg, G. M. Modulation of liposomal membrane fluidity by flavonoids and isoflavonoids. Arch Biochem Biophys, 373: 102-109, 2000.

[121]. Shapiro, A. B., and Ling, V. Effect of quercetin on Hoechst 33342 transport by purified and reconstituted P-glycoprotein. Biochem Pharmacol, 53: 587-596, 1997.

[122]. Boumendjel, A., Di Pietro, A., Dumontet, C., and Barron, D. Recent advances in the discovery of flavonoids and analogues with high affinity binding to P-glycoprotein responsible for cancer cell multidrug resistance. . Med. Res. Rev., 22: 512-529, 2002.

[123]. Tamai, I., and Safa, A. R. Azidopine noncompetitively interacts with vinblastine and cyclosporin A binding to P-glycoprotein in multidrug resistant cells. J Biol Chem, 266: 16796-16800, 1991.

[124]. Conseil, G., Baubichon-Cortay, H., Dayan, G., Jault, J. M., Barron, D., and Di Pietro, A. Flavonoids: a class of modulators with bifunctional interactions at vicinal ATP- and steroid-binding sites on mouse Pglycoprotein. . Proc Natl Acad Sci USA, 95: 9831-9836, 1998.

[125]. Boumendjel, A., Beney, C., Deka, N., Mariotte, A. M., Lawson, M. A., Trompier, D., Baubichon-Cortay, H., and Di Pietro, A. 4-Hydroxy-6-methoxyaurones with highaffinity binding to cytosolic domain of $\mathrm{P}$ glycoprotein. Chem. Pharm. Bull., 50: 854856, 2002.

[126]. Critchfield, J. W., Welsh, C. J., Phang, J. M., and Yeh, G. C. Modulation of adriamycin accumulation and efflux by flavonoids in HCT-15 colon cells: activation of Pglycoprotein as a putative mechanism. . Biochem. Pharmacol., 48: 1437-1445, 1994.

[127]. Phang, J. M., Poore, C. M., Lopaczynska, J., and Yeh, G. C. Flavonol stimulated efflux of 7,12-dimethylbenz(a)-anthracene multidrug-resistant breast cancer cells. Cancer Res., 53: 5977-5981, 1993.

[128]. Ferte', J., Ku“ hnel, J.-M., Chapuis, G., Rolland, Y., Lewin, G., and Schwaller, M. A. Flavonoid-related modulators of multidrug resistance: synthesis, pharmacological activity, and structure activity relationships. J. Med. Chem., 42: 478-489, 1999.

[129]. Chiba, P., Holzer, W., Landau, M., Bechmann, G., Lorenz, K., Plagens, B., Hitzler, M., Richter, E., and Ecker, G. Substituted 4-acylpyrazoles and 4acylpyrazolones: synthesis and multidrug resistance-modulating activity. J. Med. Chem. , 41: 4001-4011, 1998.

[130]. Ecker, G., Huber, M., Schmid, D., and Chiba, $P$. The importance of a nitrogen atom in modulators of multidrug resistance. Mol. Pharmacol. Res., 56: 791-796, 1999.

[131]. Hiessbock, R., Wolf, C., Richter, E., Hitzler, M., Chiba, P., Kratzel, M., and Ecker, G. Synthesis and in vitro multidrug resistance modulating activity of a series of dihydrobenzopyrans and tetrahydroquinolines. J. Med. Chem. , 42: 1921-1926, 1999.

[132]. Versantvoort, C. H. M., Schuurhuis, G. J., Pinedo, H. M., Eekman, C. A., Kuiper, C. M., Lankelma, J., and Broxterman, H. J. Genistein modulates the decreased drug accumulation in non P-glycoprotein mediated multidrug resistant tumour cells. . Br. J. Cancer, 68: 939-946, 1993.

[133]. Hadjeri, M., Barbier, M., Ronot, X., Mariotte, A. M., Boumendjel, A., and Boutonnat, J. Modulation of P-glycoprotein-mediated multidrug resistance by flavonoid derivatives and analogues. J Med Chem, 46: 2125-2131, 2003.

[134]. Comte, G., Daskiewicz, J.-B., Bayet, C., Conseil, G., Vornery-Vanier, A., Dumontet, C., Di Pietro, A., and Barron, D. Cisoprenylation of flavonoids enhances affinity toward P-glycoprotein and modulation of cancer cell chemoresistance. . J. Med. Chem., 44: 763-768, 2001.

[135]. Cooray, H. C., Janvilisri, T., van Veen, H. W., Hladky, S. B., and Barrand, M. A. Interaction of the breast cancer resistance protein with plant polyphenols. Biochem. Biophys. Res. Commun., 317: 269-275, 2004.

[136]. van Zanden, J. J., Wortelboer, H. M., Bijlsma, S., Punt, A., Usta, M., Bladeren, P. J., Rietjens, I. M., and Cnubben, N. H. Quantitative structure activity relationship studies on the flavonoid mediated inhibition of multidrug resistance proteins 1 and 2 . . Biochem. Pharmacol., 69: 699-708, 2005.

[137]. Guengerich, F. P., and Kim, H. D. In vitro inhibition of dihydropyridine oxidation and aflatoxin B1 activation in human liver 
microsomes by naringenin and other flavonoids. Carcinogenesis, 11: 2275-2279, 1990.

[138]. Miniscalco, A., Landahl, J., Regardh, C. G., Edgar, B., and Eriksson, U. G. Inhibition of dihydropyridine in rat and human liver microsomes by flavonoids found in grapefruit juice. J. Pharmacol. Exp. Ther., 261: 11951198, 1992.

[139]. Hsiu, S. L., Hou, Y. C., Wang, Y. H., Tsao, C. W., Su, S. F., and Chao, P. D. Quercetin significantly decreased cyclosporin oral bioavailability in pigs and rats. Life Sci, 72: 227-235, 2002.

[140]. Shapiro, A. B., and Ling, V. Stoichiometry of coupling of rhodamine 123 transporter to hydrolysis by human $\mathrm{P}$ glycoprotein. Eur J Biochem, 254: 189-193, 1998.

[141]. Broder, S., Duchin, K. L., and Selim, S., Method, compositions and kits for increasing the oral bioavailability of pharmaceutical agents Baker Norton Pharmaceuticals, Inc., US Patent No. 7,041,640 (2006).

[142]. Inomata, K., Takahashi, T., Inoue, H., Yanai, M., Yamazaki, H., Suzuki, M., Takasawa, T., Kawamura, K., Oshida, N., Ikemoto, H., and Kishiye, T., Multidrug resistance inhibitors, Nisshin Flour Milling Co., Ltd., US Patent No. 6,011,069 (2000).

[143]. Schellens, J. H. M., and Schinkel, A. H., Method of improving bioavailability of orally administered drugs, a method of screening for enhancers of such bioavailability and novel pharmaceutical compositions for oral delivery of drugs, Cancer Research Ventures Limited, US Patent No. 7,030,132 (2006).

[144]. Schinkel, A. H., Mol, C. A., Wagenaar, E., van Deemter, L., Smit, J. J., and Borst, P. Multidrug resistance and the role of $\mathrm{P}$ glycoprotein knockout mice. Eur J Cancer, 31A: 1295-1298, 1995.

[145]. Breedveld, P., Pluim, D., Cipriani, G., Wielinga, P., van Tellingen, O., Schinkel, A. H., and Schellens, J. H. The effect of Bcrp1 (Abcg2) on the in vivo pharmacokinetics and brain penetration of imatinib mesylate (Gleevec): implications for the use of breast cancer resistance protein and P-glycoprotein inhibitors to enable the brain penetration of imatinib in patients. Cancer Res, 65: $2577-$ 2582, 2005.

[146]. Allen, J. D., Van Dort, S. C., Buitelaar, M., van Tellingen, O., and Schinkel, A. H. Mouse breast cancer resistance protein (Bcrp1/Abcg2) mediates etoposide resistance and transport, but etoposide oral availability is limited primarily by P-glycoprotein. Cancer Res, 63: 1339-1344, 2003.

[147]. Leu, B. L., and Huang, J. D. Inhibition of intestinal P-glycoprotein and effects on etoposide absorption. Cancer Chemother. Pharmacol., 35: 432-436, 1995.

[148]. Creemers, G. J., Gerrits, C. J., Eckardt, J. R., Schellens, J. H., Burris, H. A., Planting, A. S., Rodriguez, G. I., Loos, W. J., Hudson, I., Broom, C., Verweij, J., and Von Hoff, D. D. Phase I and pharmacologic study of oral topotecan administered twice daily for 21 days to adult patients with solid tumors. J Clin Oncol, 15: 1087-1093, 1997.

[149]. Jonker, J. W., Smit, J. W., Brinkhuis, R. F., Maliepaard, M., Beijnen, J. H., Schellens, J. H., and Schinkel, A. H. Role of breast cancer resistance protein in the bioavailability and fetal penetration of topotecan. J Natl Cancer Inst, 92: 1651-1656, 2000.

[150]. Zamboni, W. C., Bowman, L. C., Tan, M., Santana, V. M., Houghton, P. J., Meyer, W. H., Pratt, C. B., Heideman, R. L., Gajjar, A. J., Pappo, A. S., and Stewart, C. F. Interpatient variability in bioavailability of the intravenous formulation of topotecan given orally to children with recurrent solid tumors. Cancer Chemother Pharmacol, 43: 454-460, 1999.

[151]. Borst, P., and Schinkel, A. H. Genetic dissociation of the function of mammalian Pglycoproteins. Trends Genet, 13: 217-222, 1997.

[152]. Meerum Terwogt, J. M., Beijnen, J. H., ten Bokkel Huinink, W. W., Rosing, H., and Schellens, J. H. Co-administration of cyclosporin enables oral therapy with paclitaxel. Lancet, 352: 285, 1998.

[153]. Schinkel, A. H., Smit, J. J., van Tellingen, O., Beijnen, J. H., Wagenaar, E., van Deemter, L., Mol, C. A., van der Valk, M. A., RobanusMaandag, E. C., te Riele, H. P., and et al. Disruption of the mouse mdrla Pglycoprotein gene leads to a deficiency in the blood-brain barrier and to increased sensitivity to drugs. Cell, 77: 491-502, 1994.

[154]. Sparreboom, A., Asperen, J. V., Mayer, U., Schinkel, A. H., Smit, J. W., Meijer, D. K. F., Nooijen, W. J., Beijnen, J. H., and Tellingen, O. V. Limited oral bioavailability and active epithelial excretion of paclitaxel (Taxol) caused by P-glycoprotein in the intestine. Proc. Natl. Acad. Sci. USA, 94: 2031-2035, 1997.

[155]. van Asperen, J., van Tellingen, O., Sparreboom, A., Schinkel, A. H., Borst, P., Nooijen, W. J., and Beijnen, J. H. Enhanced oral bioavailability of paclitaxel in mice treated with the P-glycoprotein blocker SDZ PSC 833. Br J Cancer, 76: 1181-1183, 1997.

[156]. Malingre, M. M., Richel, D. J., Beijnen, J. H., Rosing, H., Koopman, F. J., Ten Bokkel Huinink, W. W., Schot, M. E., and Schellens, J. H. Coadministration of cyclosporine 
strongly enhances the oral bioavailability of docetaxel. J Clin Oncol, 19: 1160-1166, 2001.

[157]. Hsiao, P., Bui, T., Ho, R. J., and Unadkat, J. D. In vitro-to-in vivo prediction of $\mathrm{P}$ glycoprotein-based drug interactions at the human and rodent blood-brain barrier. Drug Metab Dispos, 36: 481-484, 2008.

[158]. Syvanen, S., Hooker, A., Rahman, O., Wilking, H., Blomquist, G., Langstrom, B., Bergstrom, M., and Hammarlund-Udenaes, M. Pharmacokinetics of P-glycoprotein inhibition in the rat blood-brain barrier. J Pharm Sci, 97: 5386-5400, 2008.

[159]. Fellner, S., Bauer, B., Miller, D. S., Schaffrik, M., Fankhanel, M., Spruss, T., Bernhardt, G., Graeff, C., Farber, L., Gschaidmeier, H., Buschauer, A., and Fricker, G. Transport of paclitaxel (Taxol) across the blood-brain barrier in vitro and in vivo. J Clin Invest, 110: 1309-1318, 2002.

[160]. Mayer, U., Wagenaar, E., Dorobek, B., Beijnen, J. H., Borst, P., and Schinkel, A. H. Full blockade of intestinal P-glycoprotein and extensive inhibition of blood-brain barrier Pglycoprotein by oral treatment of mice with PSC833. J. Clin. Invest., 100: 2430-2436, 1997.

[161]. Schinkel, A. H., Wagenaar, E., Mol, C. A. A. M., and van Deemter, L. P-glycoprotein in the blood-brain barrier of mice influences the brain penetration and pharmacological activity of many drugs. J. Clin. Invest., 97: 2517-2524, 1996.

[162]. Hsieh, Y. J., Chang, C. H., Huang, S. P., Lin, C. W., Wang, M. N., Wu, Y. T., Chen, Y. J., and Tsai, T. H. Effect of cyclosporin A on the brain regional distribution of doxorubicin in rats. Int J Pharm, 350: 265-271, 2008.

[163]. Bihorel, S., Camenisch, G., Lemaire, M., and Scherrmann, J. M. Modulation of the brain distribution of imatinib and its metabolites in mice by valspodar, zosuquidar and elacridar. Pharm Res, 24: 1720-1728, 2007.

[164]. Dai, H., Marbach, P., Lemaire, M., Hayes, M., and Elmquist, W. F. Distribution of STI-571 to the brain is limited by P-glycoprotein mediated efflux. J Pharmacol Exp Ther, 304: 1085-1092, 2003.

[165]. Decleves, X., Bihorel, S., Debray, M., Yousif, S., Camenisch, G., and Scherrmann, J. M. $\mathrm{ABC}$ transporters and the accumulation of imatinib and its active metabolite CGP74588 in rat C6 glioma cells. Pharmacol Res, 57: 214-222, 2008.

[166]. Hamada, A., Miyano, H., Watanabe, H., and Saito, H. Interaction of imatinib mesilate with human P-glycoprotein. J Pharmacol Exp Ther, 307: 824-828, 2003.

[167]. Bosch, T. M. Pharmacogenomics of drugmetabolizing enzymes and drug transporters in chemotherapy. Methods Mol Biol, 448: 6376, 2008.

[168]. Walle, T., Walle, K., Kumar, G. N., and Bhalla, K. N. Taxol metabolism and disposition in cancer patients. Drug Metabol Dispos, 23: 506-512, 1995.

[169]. Schellens, J. H. M., Malingre, M. M., Marielle, C., Kruijtzera, F., Bardelmeijera, H. A., van Tellingen, O., Schinkel, A. H., and Beijnen, J. H. Modulation of oral bioavailability of anticancer drugs: from mouse to man. Eur J Pharm Sci, 12: 103-110, 2000.

[170]. Iyer, L., Ramirez, J., Shepard, D. R., Bingham, C. M., Hossfeld, D. K., Ratain, M. J., and Mayer, U. Biliary transport of irinotecan and metabolites in normal and Pglycoprotein-deficient mice. Cancer Chemother Pharmacol, 49: 336-341, 2002.

[171]. Tobin, P. J., Hong, Y., Seale, J. P., Rivory, L. P., and McLachlan, A. J. Loperamide inhibits the biliary excretion of irinotecan (CPT-11) in the rat isolated perfused liver. J Pharm Pharmacol, 57: 39-45, 2005.

[172]. Chico, I., Kang, M. H., Bergan, R., Abraham, J., Bakke, S., Meadows, B., Rutt, A., Robey, R., Choyke, P., Merino, M., Goldspiel, B., Smith, T., Steinberg, S., Figg, W. D., Fojo, T., and Bates, S. Phase I study of infusional paclitaxel in combination with the Pglycoprotein antagonist PSC 833. J Clin Oncol, 19: 832-842, 2001

[173]. Meerum Terwogt, J. M., Malingre, M. M., Beijnen, J. H., ten Bokkel Huinink, W. W., Rosing, H., Koopman, F. J., van Tellingen, O., Swart, M., and Schellens, J. H. Coadministration of oral cyclosporin A enables oral therapy with paclitaxel. Clin Cancer Res, 5: 3379-3384, 1999.

[174]. Mistry, P., Stewart, A. J., Dangerfield, W., Okiji, S., Liddle, C., Bootle, D., Plumb, J. A., Templeton, D., and Charlton, P. In vitro and in vivo reversal of P-glycoprotein-mediated multidrug resistance by a novel potent modulator, XR9576. Cancer Res, 61: 749758, 2001.

[175]. Newman, M. J., Rodarte, J. C., Benbatoul, K. D., Romano, S. J., Zhang, C., Krane, S., Moran, E. J., Uyeda, R. T., Dixon, R., Guns, E. S., and Mayer, L. D. Discovery and characterization of OC144-093, a novel inhibitor of P-glycoprotein-mediated multidrug resistance. Cancer Res, 60: 29642972, 2000.

[176]. Rowinsky, E. K., Smith, L., Wang, Y. M., Chaturvedi, P., Villalona, M., Campbell, E., Aylesworth, C., Eckhardt, S. G., Hammond, L., Kraynak, M., Drengler, R., Stephenson, J., Jr., Harding, M. W., and Von Hoff, D. D. Phase I and pharmacokinetic study of 
paclitaxel in combination with biricodar, a novel agent that reverses multidrug resistance conferred by overexpression of both MDR1 and MRP. J Clin Oncol, 16: 2964-2976, 1998.

[177]. Giaccone, G., Linn, S. C., Welink, J., Catimel, G., Stieltjes, H., van der Vijgh, W. J., Eeltink, C., Vermorken, J. B., and Pinedo, H. M. A dose-finding and pharmacokinetic study of reversal of multidrug resistance with SDZ PSC 833 in combination with doxorubicin in patients with solid tumors. Clin Cancer Res, 3: 2005-2015, 1997.

[178]. Sparreboom, A., Planting, A. S., Jewell, R. C., van der Burg, M. E., van der Gaast, A., de Bruijn, P., Loos, W. J., Nooter, K., Chandler, L. H., Paul, E. M., Wissel, P. S., and Verweij, J. Clinical pharmacokinetics of doxorubicin in combination with GF120918, a potent inhibitor of MDR1 P-glycoprotein. Anticancer Drugs, 10: 719-728, 1999.

[179]. Horio, M., Chin, K. V., Currier, S. J., Goldenberg, S., Willams, C., Pastan, I., Gottesman, M. M., and Handler, J. Transepithelial transport of drugs by the multidrug transporter in cultured Madin-Darby canine kidney cell epithelia. J. Biol. Chem., 264 14880-14884, 1989.

[180]. Arimori, K., Kuroki, N., Hidaka, M., Iwakiri, T., Yamsaki, K., Okumura, M., Ono, H., Takamura, N., Kikuchi, M., and Nakano, M. Effect of P-glycoprotein modulator, cyclosporin A, on the gastrointestinal excretion of irinotecan and its metabolite SN38 in rats. Pharm Res, 20: 910-917, 2003.

[181]. Gupta, E., Safa, A. R., Wang, X., and Ratain, M. J. Pharmacokinetic modulation of irinotecan and metabolites by cyclosporin A. Cancer Res, 56: 1309-1314, 1996.

[182]. Huang, S., and Lesko, L. J. Drug-Drug, DrugDietary Supplement, and Drug-Citrus Fruit and Other Food Interactions: What Have We Learned? J Clin Pharmacol, 44: 559-569, 2004.

[183]. Wagner, D., Spahn-Langguth, H., Hanafy, A., Koggel, A., and Langguth, P. Intestinal drug efflux: formulation and food effects. Adv. Drug Deliv. Rev., 50 Suppl 1: S13-31., 2001.

[184]. Wang, E., Casciano, C. N., Clement, R. P., and Johnson, W. W. Inhibition of Pglycoprotein transport function by grapefruit juice psoralen. Pharm. Res., 18: 432-438, 2001.

[185]. Choi, C. H. ABC transporters as multidrug resistance mechanisms and the development of chemosensitizers for their reversal. Cancer Cell International, 5: 30-42, 2005.

[186]. Gottesman, M. M. How cancer cells evade chemotherapy: Sixteenth Richard and Hinda Rosenthal Foundation Award Lecture. Cancer Res, 53: 747-754, 1993.
[187]. Goldstein, L. J., Galski, H., Fojo, A., Willingham, M., Lai, S., Gazdar, A., Pirker, R., Green, A., Crist, W., Brodeur, G. M., Lieber, M., Cossman, J., Gottesman, M. M., and Pastan, I. Expression of a multidrug resistance gene in human tumors. J. Natl. Canc. Inst., 81: 116-124, 1989.

[188]. Zhang, Y., Bachmeier, C., and Miller, D. W. In vitro and in vivo models for assessing drug efflux transporter activity. Adv. Drug Del. Rev., 55: 31-51, 2003.

[189]. Tiberghien, F., and Loor, F. Ranking of Pglycoprotein substrates and inhibitors by a calcein-AM fluorometry screening assay. Anti-cancer Drugs, 7: 568-578, 1996.

[190]. Scala, S., Akhmed, N., Rao, U. S., Paull, K., Lan, L.-B., Dickstein, B., Lee, J.-S., Elgemeie, G. H., Stein, W. D., and Bates, S. E. P-Glycoprotein Substrates and Antagonists Cluster into Two Distinct Groups Mol. Pharmacol. Res., 51: 1024-1033, 1997.

[191]. Zamora, J. M., Pearce, H. L., and Beck, W. T. Essential features of the P-glycoprotein pharmacophore as defined by a series of reserpine analogs that modulate multidrug resistance. Mol. Pharmacol., 33: 454-462, 1988.

[192]. Seelig, A., and Landwojtowicz, E. Structureactivity relationship of P-glycoprotein substrates and modifiers. Eur. J. Pharm. Sci., 12: 31-40, 2000.

[193]. Hochman, J. H., Yamazaki, M., Ohe, T., and Lin, J. H. Evaluation of Drug Interactions with P-Glycoprotein in Drug Discovery: In Vitro Assessment of the Potential for DrugDrug Interactions with P-Glycoprotein. Current Drug Metabolism, 3: 257-273, 2002.

[194]. Stouch, T. R., and Gudmundsson, O. Progress in understanding the structure-activity relationships of P-glycoprotein. Adv Drug Deliv Rev, 54: 315-328, 2002.

[195]. Muenster, U., Grieshop, B., Ickenroth, K., and Gnoth, M. J. Characterization of substrates and inhibitors for the in vitro assessment of Bcrp mediated drug-drug interactions. Pharm Res, 25: 2320-2326, 2008.

[196]. Dhainaut, A., Regnier, G., Tizot, A., Pierre, A., Leonce, S., Guilbaud, N., Kraus-Berthier, L., and Atassi, G. New purines and purine analogs as modulators of multidrug resistance. J. Med. Chem. , 39: 4099-4108, 1996.

[197]. Beck, W. T., and Qian, X. D. Photoaffinity substrates for P-glycoprotein. Biochem. Pharmacol., 43: 89-93, 1992.

[198]. Kessel, D., Beck, W. T., Kukuruga, D., and Schulz, V. Characterization of multidrug resistance by fluorescent dyes. Cancer Res., 51: 4665-4670, 1991.

[199]. Schaich, M., Neu, S., Beck, J., Gekeler, V., Schuler, U., and Ehninger, G. A novel method 
for direct and fluorescence independent determination of drug efflux out of leukemic blast cells. . Leukemia Res. , 21: 933-940, 1997.

[200]. Balimane, P. V., Han, Y. H., and Chong, S. Current Industrial Practices of Assessing Permeability and P-Glycoprotein Interaction. The AAPS Journal 8: Article 1; E1-13, 2006.

[201]. Litman, T., Zeuthen, T., Skovsgaard, T., and Stein, W. D. Structure activity relationships of P-glycoprotein interacting drugs: kinetic characterization of their effects on ATPase activity Biochim. Biophys. Acta, 1361: 159168, 1997.

[202]. Scarborough, G. A. Drug-stimulated ATPase activity of the human P-glycoprotein. J. Bioenerg. Biomembr., 27: 37-41, 1995.

[203]. Chen, C., Liu, X., and Smith, B. J. Utility of Mdr1-Gene Deficient Mice in Assessing the Impact of P-glycoprotein on Pharmacokinetics and Pharmacodynamics in Drug Discovery and Development. Current Drug Metabolism, 4: 272-291, 2003. 